Max-Planck-Institut für demografische Forschung

Max Planck Institute for Demographic Research

Konrad-Zuse-Strasse 1 - D-18057 Rostock - GERMANY

Tel +49 (0) 3812081 - 0; Fax +49 (0) 3812081 - 202;

http://www.demogr.mpg.de

MPIDR WORKING PAPER WP 2012-026

AUGUST 2012

\title{
Quantifying the role \\ of alternative pension reforms \\ on the Austrian economy
}

\author{
Miguel Sánchez-Romero (msanchez@demogr.mpg.de) \\ Jože Sambt \\ Alexia Prskawetz
}

This working paper has been approved for release by: Michaela Kreyenfeld (kreyenfeld@demogr.mpg.de), Deputy Head of the Laboratory of Economic and Social Demography.

(c) Copyright is held by the authors.

Working papers of the Max Planck Institute for Demographic Research receive only limited review. Views or opinions expressed in working papers are attributable to the authors and do not necessarily reflect those of the Institute. 


\title{
Quantifying the role of alternative pension reforms on the Austrian economy*
}

\author{
Miguel Sánchez-Romero \\ Max Planck Institute for Demographic Research (MPIDR) \\ Jože Sambt \\ Faculty of Economics, University of Ljubljana, Slovenia; \\ Vienna University of Technology (TU) \\ Alexia Prskawetz \\ Institute of Mathematical Methods in Economics, Research Unit Economics, \\ Vienna University of Technology (TU); \\ Vienna Institute of Demography, Austrian Academy of Sciences (VID); \\ Wittgenstein Centre of Demography and Global Human Capital (WIC)
}

\begin{abstract}
This paper investigates the role of recent pension reforms for the development of the social security system and economic growth in Austria. We use a computable general equilibrium model that is built up of overlapping generations that differ by their household structure, longevity, educational attainment, and capital accumulation. Each household optimally decides over its consumption paths, work effort, and retirement age according to the life-cycle theory of labor, while they face survival risk. We find that the pension reforms implemented from 2000 to 2004, although in the correct direction, are not sufficient to solve the labor market distortion caused by the Austrian PAYG pension system. Using alternative policy options, our simulations indicate that a change to a notional defined contribution system and an increase in the educational distribution of the work force would increase the incentive for later retirement ages and thereby increase labor supply and economic growth.
\end{abstract}

Keyword: aging; social security; retirement; overlapping generations. JEL: D58; D91; H55; J11; J26

\footnotetext{
*The authors would like to thank Christian Keuschnigg, Bernhard Hammer, Anne Goujon, Elke Loichinger, Ramon Bauer, the seminar participants at Aging and Productivity Workshop in St. Gallen, and two referees for valuable comments and help on data collection. Also, we would like to express our indebtedness to Ronald Lee, Carl Boe, and Carl Mason for their assistance in our computations. The authors acknowledge funding from the Austrian Science Fund (FWF) under project number I347-G16 and the Max Planck Institute for Demographic Research (MPIDR).
} 


\section{Motivation}

Persistent low fertility together with increasing survival to old age and moderate levels of migration will shape the future age structure in Austria. As a consequence of these demographic trends an aging and shrinking of the labor force is foreseen. These trends are reinforced by the baby boom generation which will start retiring in the next years. In addition to these demographic conditions, institutional settings of the labor market have led to a decrease in the working life span during the last decades. Later entry into the labor force accompanied with early retirement ages have further reduced the labor supply. Faced with these demographic and institutional conditions that raise the ratio of retired to working people in Austria, it is important to investigate the role of the recent pension reforms for the development of the social security systems and economic growth.

We start from a computable general equilibrium model that is built up of overlapping generations that differ by their household structure, longevity, educational attainment, and capital accumulation. Each household optimally decides over its consumption paths, the intensity of work, and retirement age and hence indirectly determines its life cycle savings. We calibrate our model to the historical time path of retirement behavior and key aggregate economic figures in Austria. The model is then applied to yield forecasts of labor market characteristics at the intensive and extensive margin together with financial and macroeconomic indicators like the financial wealth to output ratio, consumption per capita, output per capita, etc. We contrast the current pension reforms with alternative pension reform and educational scenarios.

Different to other CGE models that deal with population aging and pension reforms, the main contribution of our model is threefold. First, we incorporate very detailed demographic structures, more specifically we account for the changing household structure (family size) and survival probabilities. Second, we study the transitional time path from the current population structure to a new stable population model while previous models often only focus on the current and future stable population model ignoring the demographic transition in between. Third, we take into consideration that workers with different educational level are imperfect substitutes in the production function. The latter fact allows us to investigate the role of educational reforms as they may interact with pension reforms and long run economic growth.

The paper is structured as follows. In Section 2 we briefly review the relevant literature with a focus on the Austrian situation. In Section 3 we introduce the Austrian pension system and its reforms of 2000, 2003 and 2004. Since early retirement is a common pathway to leave the labor force in Austria we particularly focus on the role of the pension reforms for this exit strategy (see Mara and Narazani (2001) for a recent study on labour-incentive reforms at preretirement age). The modeling framework is introduced in Section 4. We assume an exogenous path of family size, mortality, and educational transition. The labor income of households depends on age, cohort, and educational attainment. Households derive positive utility from consumption per household member and 
negative disutility of work. Consumption, taxes and assets have to be financed out of asset returns and income. We next introduce the two-step household optimization. First the household head chooses the optimal consumption path and number of hours worked for a fixed retirement age and in a second stage the household age chooses optimal retirement. After having introduced the household optimization we review the firm's behavior, which combines three imperfectly substitutable types of labor: low, medium, and high skill workers, and define the government revenues and expenditures. Section 5 introduces the general equilibrium of our economy. The calibration process and the data used are summarized in Section 6. The results and findings of our model are summarized in Section 7. In particular, we introduce alternative pension policies and present the results always relative to the status quo of the Austrian pension system. The final section is devoted to a discussion of our simulation results and concludes.

\section{Previous literature}

The Austrian pension system and in particular its reform options have recently been investigated within computable general equilibrium (CGE) models in a series of papers by Keuschnigg and Keuschnigg (2004), Fisher and Keuschnigg (2010) and Jaag et al. (2010). The underlying framework of those papers is an extension of the life cycle model by Gertler (1999). An important novel contribution by the papers by Keuschnigg is the incorporation of endogenous labor market supply allowing to investigate in more detail labor market distortions caused by alternative pension reforms.

As the work by Gruber and Wise $(1999,2004,2007)$ clearly identified, a major concern of many pension systems is the fact that they induce quite high implicit tax rates on continued labor supply at older age. For Austria Hofer and Koman (2006) showed that disincentives for continued work are quite large after the early retirement age.

In Keuschnigg and Keuschnigg (2004) a detailed labor market model based on recent models of job search activities by unemployed people and job creations by firms is introduced in a CGE model. Within this framework the authors study the role of three alternatives to increase the sustainability of the pension systems. These include the option of increasing retirement age, reducing benefits or increasing contribution rates. The former two options are shown to have strong effects on reducing unemployment by increasing job search intensities.

As argued in Fisher and Keuschnigg (2010) any pension reform needs to carefully consider its implications for labor market incentives distinguishing between prime-age workers and workers near their retirement age. Indeed as the authors show, an increase in retirement ages without adequate adjustments in the pension system - might even be counterbalanced by increasing implicit tax rates on prime-age workers, thereby lowering their labor supply. As the authors show, harmonizing the pension system and increasing the tax-benefit link may however work to increase labor supply at the intensive margin for prime-age 
workers and at the extensive margin for workers near their retirement. Furthermore the authors demonstrate that the closer the pension system takes into account actuarially fairness the more likely the goal of increasing overall labor supply will be achieved.

In Jaag et al. (2010) further analytical results on labor market effects of pension reforms for prime age workers and retirement behavior are presented. In particular the following four options of pension reforms for Austria are considered: increasing the tax benefit link, changing from wage to price indexation, extending the period on which pensions are calculated and increasing the actuarial fairness of pensions. Through a set of calibrated simulations the authors show that those reforms may positively affect labor intensity at young ages, reduce unemployment and increase retirement ages. In addition welfare gains through increased economic growth are to be expected.

So far we have reviewed the relevant Austrian literature. More generally our paper is close to recent work by Imrohoroglu and Kitao (2012) and the work cited therein (though we do not account for individual health and productivity shocks as in their model). As the authors demonstrate, pension reforms will mainly work through changes in life-cycle savings and labor supply. We will illustrate a similar result in our model and the various simulation results on alternative pension reforms we present. One of the specific features of our model is the assumption that workers with different educational level may be imperfectly substitutable in the production function. See Prskawetz et al. (2008) for a general discussion on the role of labor demand factors - in addition to labor supply factors - on labor productivity. In Rojas (2005) these assumptions on the labor demand side have been included in a CGE model of the Spanish economy to evaluate the necessary social security reforms as required by the changing demographic structure. Our model setup will allow us to conduct a similar study and investigate the role of imperfect substitutability of workers at different educational level for the performance of the Austrian pension system and economic growth. Similar to Rojas (2005), however, we are also facing the problem that we cannot rely on empirical estimates of the degree of substitutability of workers and have to conduct a sensitivity analysis.

\section{Pension reforms in Austria}

The Austrian pension system is dominated by the public pay as you go (PAYG) system, which is mandatory and of the defined benefit form. It covers old age and invalidity pensions, but also indirect benefits such as survivors and orphans pensions (Knell et al., 2006, p. 70). The pensions system in Austria is characterized by a low labor force participation of older workers. In 2009, $42 \%$ of individuals aged 55-64 years were employed or looking for a job, while the OECD average was $57 \%$ (Staubli and Zweimüller, 2011, p. 3). In addition to relatively low ages of regular retirement additional pathways into early retirement exist. These include amongst others, the options to retire directly out of long-term unemployment, reduced working capacity and disability status. Continuous 
expansion of early retirement options lowered average retirement age by four years for men and almost three years for women in only one decade from 1974 through 1984. Early retirement was partially used also as a tool for mitigating growing unemployment. In the 1980s, long term fiscal sustainability of the pension system became a key issue, but consecutive pension reforms in the 1990s were not strong enough (OECD, 2005, p. 87). We present main features of the three pension reforms that followed during the first decade of the XXI century, having more substantial positive impact on long term fiscal sustainability. They were aiming at increasing effective age at retirement and reducing the generosity of the mandatory state pension system (Knell et al., 2006, p. 69).

Normal retirement age Historically normal retirement age was 65 for men and 60 for women. The Constitutional Court ruled out this gender difference on the principle of equal treatment between sexes. The adjustment period for the women's normal retirement age is 2004-2033, increasing by 2 months per year - from 60 years in 2003 to 65 years in $2034 .^{1}$

Early retirement Until 2000 early retirement age was 60 years for men and 55 years for women. After the pension reform in 2000, they were gradually increasing by 0.5 years per year (reaching 61.5 years for men and 56.5 years for women in 2003). With the reform in 2003, early retirement ages are further increasing by 0.25 years per year. For men, the transition period was finished in 2006 by reaching 62 years, while for women it continues till 2018 when it will be 60 years. Thereafter prolongation for women will slow down to 0.2 years annually until equalizing with men on 62 years in 2028. With the reform in 2004 an additional condition for retirement was introduced, requiring at least 37.5 years of active labor force participation. Early retirement through the unemployment channel was abolished with the reform of 2003.

Pension benefits Regardless of the specific pension system in place, all pensions share a common formula for calculating the initial pension:

$$
\text { Initial pension }=\text { accrual rate } \times \text { pension assessment base. }
$$

Until 2004 existing pensions were adjusted according to complicated adjustment methods which turned out to be close to the consumer price index, while in the reform of 2004 the indexation of existing pensions to consumer price index is established also de iure. The pension formula is comprised of several parameters, which have been changed in each reform. Next, we summarize those changes.

Before 2000, the initial pension benefits of an individual who retired at the normal age of retirement was $80 \%$ of her/his average labor income of the best 15 years in the labor market, which usually corresponds to the last years in the

\footnotetext{
${ }^{1}$ In the model, we do not differentiate between men and women. Assuming the number of men and women claiming benefits are the same for each cohort, then the gradual increase in retirement age for both sexes combined is from 62.5 years in 2003 to 65 in 2034 (increasing by 1 month per year).
} 
labor market. If persons reached at least early retirement age the accrual rate was $2 \%$ for each year in the labor market but with the ceiling on $80 \%$ of the pension assessment base. For less than 15 years in the labor market, persons received $30 \%$ of the pension assessment base.

The reform of 2000 increased penalization of early retirement and introduced a reward for late retirement. The deduction of pension entitlements for early retirement increased to 3 percentage points per year, being limited to maximal deduction of 10.5 accrual points or $15 \%$ of pension entitlements. Work beyond the normal retirement age was rewarded by 4 percentage points per year for the first three additional years.

The reform of 2003 introduced further adjustment on the initial pension benefits: a) the accrual rate gradually declined from $2 \%$ per year in 2003 to $1.78 \%$ in 2009 ; b) both the penalization for early retirement and the reward for late retirement was set to $4.2 \%$ per year; c) the average number of years for calculating the pension assessment base was proposed to increase gradually by one year annually from the best 15 years to the best 40 years in 2028 .

The reform of 2004 introduced individual defined benefit pension accounts within the PAYG system for workers born after January 1st, 1955. In particular, their pension entitlements are calculated as a mix of old and new provisions while those born before January 1st, 1955 are exempt from the new system (Knell et al., 2006, p. 75). In practice the adjustment of key parameters of the pension systems is subject to a political process. To our understanding the pension system still mirrors PAYG system and we therefore model it accordingly. The system follows the rule 45-65-80. That is, after 45 years of contributions and retirement at age 65 , pension benefits amount to $80 \%$ of average life earnings. Thus, the accrual rate implicitly remains at 1.78 percentage points per year. A further extension from 40 years to lifetime earnings is foreseen (for individuals who work more than 40 years).

\section{The Model}

The framework used to describe our economy is an overlapping generations model with endogenous consumption, labor supply, and retirement decisions. Time is discrete, $t \in \mathcal{T}=\{0,1, \ldots, T\}$. In each period, the population consists of 100 cohorts distributed among dependent children (ages 0-17), workers and retirees. Let us define $\mathcal{X}=\{0,1, \ldots, 100\}$ as the set of ages. The economy consists of households, which consume goods and supply capital and labor, one representative neoclassical firm that hires workers and demands capital at

competitive prices, and a government that levies taxes and social contributions in order to provide public goods and services and benefits.

\subsection{Demographics}

Individuals face mortality and fertility risk that differs by age and across cohorts. Lifetime uncertainty is represented by a standard survival probability function 
$S_{t, x}$. Let $\pi_{t, x} \geq 0$ be the conditional probability of surviving to age $x+1$ in year $t$ (with $\pi_{t, x}=0$ for all $x \geq \Omega$, where $\Omega$ is the maximum age). Thus, the probability that an individual survives at least to age $x$, conditional on being alive at age 0 , is given by

$$
S_{t, x}=\prod_{u=0}^{x-1} \pi_{t-x+u, u}, \text { where } S_{t-x, 0}=1 \text { and } S_{t-x+\Omega, \Omega}=0 .
$$

Households are comprised of one adult, or household head, and dependent children. The size of the household $\eta_{t, x} \geq 1$, expressed in units of equivalent adult consumers, is assumed to vary over time because of fertility and mortality and because children leave their parent's home (see Figure 1). The importance of time varying household composition explaining household saving has been already stressed in several papers (Curtis et al., 2011; Attanasio and Weber, 2010; Browning and Ejrnaes, 2009; Browning and Lusardi, 1996). We assume

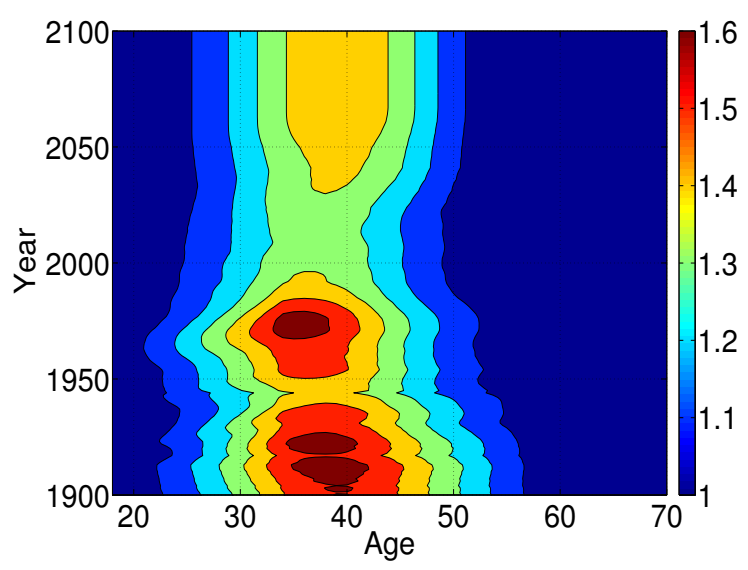

Figure 1: Number of equivalent adult consumers by age of household head from 1900 to 2100 in Austria, $\eta_{t, x}$.

Notes: An area with the same color represents households whose head supports a similar number of equivalent adult consumers. In Austria, the number of equivalent adult consumers in a household peaks when household heads are around age 40. Moreover, it is shown how $\eta$ reached values of 1.6 in the 1910s, the 1920s, and the 1970s. However, from 2050 onwards the maximum $\eta$ is around 1.4 according to the medium-variant case of the UN population projections, which assumes a future total fertility rate (TFR) of 1.67 from 2045 onwards.

that children leave their parent's home, enter into the labor market, and set up a new household at age $18\left(x_{0}\right)$. This assumption builds upon the work done in the National Transfer Accounts project for Austria that shows how individuals gradually enter into the labor market from age 15 onwards (Sambt and Prskawetz, 2011). 


\subsection{Education, retirement, and labor income}

In addition to demographic heterogeneity, we assume that adults differ by their education level. We distinguish between three mutually exclusive education groups: low, medium, and high education, represented by $i \in \mathcal{H}=\{l, m, h\}$. In this way, we can better capture wage inequalities driven by changes in the educational composition (Acemoglu and Autor, 2012). Let $\Upsilon_{t}(i)$ be the distribution function of the educational attainment of an individual born in year $t$. The educational composition and projections are based on the work by Samir et al. (2010). Moreover, we assume that the labor market participation for each worker (or labor supply at the extensive margin) is determined by an endogenous retirement decision variable $z$.

Source of labor income We distinguish three alternative cases over the lifecycle. First, if an adult works, she earns a labor income that depends upon the marginal product of labor associated to her skill group $\omega^{i}$ times her age-specific productivity $\epsilon_{x}(i)$, which also depends on her education and age, times the hours worked at that age $l_{t, x}$. Second, if the individual retires before the official early retirement age $z_{e}$, she will not receive either benefits or labor income until $z_{e}$. Last, if an individual retires after age $z_{e}$, she will claim a retirement pension benefit equal to $v_{t, x} P_{t, x}$. Thus, the net labor income at age $x$ is

$$
y_{t, x}^{i}= \begin{cases}\left(1-\tau_{l}\right)\left(1-\varsigma \tau_{s, t}\right) \omega_{t}^{i} \epsilon_{x}(i) l_{t, x} & \text { if } x_{0} \leq x<z, \\ 0 & \text { if } z \leq x<z_{e}, \\ \left(1-\tau_{l}\right) v_{t, x} P_{t, x} & \text { if } x \geq \max \left(z, z_{e}\right),\end{cases}
$$

where $\tau_{l}$ is the labor income tax rate, $\tau_{s, t}$ is the social contribution rate at age $x$, and $\varsigma$ is the fraction of the social contribution paid by the employee.

Similar to Ludwig and Reiter (2010), we assume that individuals understand the rules on how the social security wealth (denoted by $P$ ) accumulates over the life-cycle, which is given by

$$
P_{t+1, x+1}= \begin{cases}\frac{1+\tilde{r}}{\pi_{t, x}} P_{t, x}+\varsigma \tau_{s, t} \omega_{t}^{i} \epsilon_{x}(i) l_{t, x} & \text { if } x_{0} \leq x<z, \\ \frac{1+\tilde{r}}{\pi_{t, x}} P_{t, x} & \text { if } z \leq x<z_{e}, \\ \frac{1+\tilde{r}}{\pi_{t, x}} P_{t, x}-v_{t, x} P_{t, x} & \text { if } x \geq \max \left(z, z_{e}\right),\end{cases}
$$

where $\tilde{r}$ is the internal rate of return of the public pension system. We assume that $v_{t, x} P_{t, x}$ is equal to a constant pension benefit of $b(z)$ until death.

\subsection{Household's preferences and budget constraint}

Individuals follow the life-cycle theory of labor supply (Heckman and MaCurdy, 1980, 1982) under mortality risks (Yaari, 1965) and endogenous retirement decision (d'Albis and Augeraud-Véron, 2008; Heijdra and Romp, 2009; d'Albis et al., 2012). Individuals are assumed to not save with a bequest motive in mind, derive 
utility from consumption, incur disutility from labor, and maximize their lifetime utility by optimally choosing their consumption path, their intensive labor supply, and their retirement age. Moreover, we make the standard assumption that preferences are additively separable over time. The instantaneous utility function takes the following form

$$
u\left(c_{t, x}, 1-l_{t, x} ; \eta_{t, x}\right)= \begin{cases}\frac{\left(\left[\left(\frac{c_{t, x}}{\eta_{t, x}}\right)^{\eta_{t, x}}\right]^{\phi}\left(1-l_{t, x}\right)^{1-\phi}\right)^{1-\sigma}-1}{1-\sigma} & \text { if } \sigma>1, \\ \phi\left[\eta_{t, x} \log \frac{c_{t, x}}{\eta_{t, x}}\right]+(1-\phi) \log \left(1-l_{t, x}\right) & \text { if } \sigma=1,\end{cases}
$$

where $c_{t, x} \geq 0$ is the household consumption whose head is of age $x$ in year $t, \phi$ is the weight on consumption, and $\sigma$ is a measure of risk aversion, which governs the strength of the income effect. This period utility function, which builds upon Braun et al. (2009), has the following properties: i) the household head takes into account not only his own consumption and leisure but also the consumption of other family members; ii) the consumption path of the household head follows the standard Euler equation. Therefore, a marginal increase in the family size in period $t$ reduces the household' saving in that period; and iii) both the Frisch elasticity of substitution and the risk aversion coefficient change over the life-cycle because of the household size. In particular, the Frisch elasticity is

given as $\frac{1-l}{l} \frac{1-\eta \phi(1-\sigma)}{\sigma}$, and the relative risk aversion coefficient is $1-\eta \phi(1-\sigma)$ if retired and is equal to $\sigma+\phi(\sigma-1)(\eta-1)$ if working. ${ }^{2}$ Consequently, if $\sigma>1$, household heads with children become more risk averse than individuals without children.

We introduce two convenient assumptions in order to provide intuitive interpretation of our simulation results. First, we assume that there exists a perfect annuity market and, second, individuals do not face liquidity constraints. Thus, the budget constraint for a household whose head has education $i$ and is of age $x$ in year $t$ is

$$
a_{t+1, x+1}=\frac{1+\bar{r}}{\pi_{t, x}} a_{t, x}+y_{t, x}^{i}-\left(1+\tau_{c, t}\right) c_{t, x},
$$

where $a_{t, x}$ denotes assets held at age $x$ in year $t, \bar{r}=r\left(1-\tau_{k}\right)$ is the interest rate net of capital income tax, and $\tau_{c, t}$ is the consumption tax in year $t$.

\subsection{Household's decision problem}

Following a similar procedure as in d'Albis et al. (2012), Heijdra and Romp (2009), d'Albis and Augeraud-Véron (2008), households choose the optimal consumption path, hours of work, and the retirement age in two steps. First, household heads determine the consumption path and hours of work conditional on a particular retirement age $z \in \mathcal{X}$. Hence, our household heads solve the

\footnotetext{
${ }^{2}$ Note that we have skipped the age and time indeces for the sake of brevity.
} 
following decision problem recursively from age $\Omega-1$ to $x_{0}$ :

$$
\begin{aligned}
& V\left(a_{t, x}, P_{t, x} ; z\right) \\
& =\max _{c_{t, x} \geq 0, l_{t, x} \in[0,1]}\left\{u\left(c_{t, x}, 1-l_{t, x} ; \eta_{t, x}\right)+\beta \pi_{t+1, x+1} V\left(a_{t+1, x+1}, P_{t+1, x+1} ; z\right)\right\},
\end{aligned}
$$

subject to (4), (6), and the boundary conditions $a_{t-x+x_{0}, x_{0}}=P_{t-x+x_{0}, x_{0}}=$ $P_{t-x+\Omega, \Omega}=0$ and $a_{-x+\Omega, \Omega} \geq 0$. Parameter $\beta$ denotes the subjective discount factor and $V\left(a_{t, x}, P_{t, x} ; z\right)$ is the conditional expected utility on the retirement age $z$ at age $x$ in year $t$.

The household first-order conditions can be written as

$$
u_{c}\left(c_{t, x}, 1-l_{t, x} ; \eta_{t, x}\right)=\beta \pi_{t+1, x+1} V_{a}\left(a_{t+1, x+1}, P_{t+1, x+1} ; z\right)\left(1+\tau_{c, t}\right),
$$

and

$$
\begin{aligned}
& u_{1-l}\left(c_{t, x}, 1-l_{t, x} ; \eta_{t, x}\right) \\
& \quad=\beta \pi_{t+1, x+1} V_{a}\left(a_{t+1, x+1}, P_{t+1, x+1} ; z\right) \omega_{t}^{i} \epsilon_{x}(i)\left(1+\tau_{c, t}\right)\left(1-t_{t, x}^{E}\right)-\mu_{l},
\end{aligned}
$$

with

$$
1-t_{t, x}^{E}=\frac{1}{1+\tau_{c, t}}\left(\left(1-\tau_{l}\right)\left(1-\varsigma \tau_{s, t}\right)+\varsigma \tau_{s, t} \xi_{t+1, x+1}(z)\right),
$$

where $t_{t, x}^{E}$ is the effective labor income tax (also known as effective tax on hours worked), $\mu_{l}$ is the Lagrange multiplier associated to the constraint in $l_{t, x}$, and $\xi_{t, x}(z)$ is the marginal rate of substitution between public pension wealth and assets holding; i.e. $V_{P}(a, P ; z) / V_{a}(a, P ; z)$. Moreover, from Eq $(9)$ we can express the effective social contribution tax rate, denoted by $t_{t, x}^{S}$, as

$$
\varsigma \tau_{s, t}\left(1-\xi_{t+1, x+1}(z) /\left(1-\tau_{l}\right)\right) .
$$

Notice that according to (9) and (10) both the effective labor income tax and the effective social contribution tax decrease when the marginal rate of substitution between public pension wealth and assets holding increases. In Proposition 1, we characterize $\xi$ as a function of the relationship between the internal rate of return of the public pension system, $\tilde{r}$, and the market (net) interest rate, $\bar{r}$. The proof of Proposition 1 is given in B.

Proposition 1. For the cycle-model given by (3)-(7), the marginal rate of substitution between public pension wealth and assets holding satisfies that

$$
\xi_{t, x}(z) \begin{cases}>1-\tau_{l} & \text { if } \tilde{r}>\bar{r} \\ =1-\tau_{l} & \text { if } \tilde{r}=\bar{r} \\ <1-\tau_{l} & \text { if } \tilde{r}<\bar{r}\end{cases}
$$

for all $x \in \mathcal{X}$ and $t \in \mathcal{T}$. 
Proposition 1 implies that the effective social contribution tax, $t^{S}$, becomes negative (positive) when the internal rate of return of the pension system is greater (smaller) than the (net) interest rate. Hence, the effective labor income tax diminishes (increases) when $\tilde{r}>(<) \bar{r}$, since $1-t^{E}=\left(1-\tau_{l}\right)\left(1-t^{S}\right) /\left(1+\tau_{c}\right)$.

Second, based on the conditional consumption and hours of work path, household heads choose the retirement age $z^{*}$ such that maximizes the expected utility at age $x_{0}$, or

$$
z^{*}=\arg \max _{z \in \mathcal{X}} V\left(a_{t, x_{0}}, P_{t, x_{0}} ; z\right) .
$$

From Eq (12) one can derive that the optimal retirement age is determined when the marginal benefit of delaying retirement equals the expected marginal cost of continue working (d'Albis et al., 2012; Heijdra and Romp, 2009; d'Albis and Augeraud-Véron, 2008).

\subsection{Firm's problem}

Our representative firm combines capital and labor to produce a single good, which can either be saved or consumed. The production function that exhibits constant returns to scale takes the following form

$$
Y_{t}=K_{t}^{\alpha}\left(\Gamma_{t} H_{t}\right)^{1-\alpha},
$$

where $Y_{t}$ is output, $K_{t}$ is the stock of capital, $\alpha$ is the capital share, $H_{t}$ is the effective aggregate labor input, and $\Gamma_{t}$ is labor-augmenting technological progress, whose law of motion is $\Gamma_{t+1}=(1+g) \Gamma_{t}$. Aggregate capital stock evolves according to the law of motion:

$$
K_{t+1}=K_{t}(1-\delta)+I_{t},
$$

where $\delta$ is the depreciation rate of capital and $I_{t}$ is aggregate gross investment. Suppose there are three types of labor, low, medium, and high skill workers that supply $H^{l}, H^{m}$, and $H^{h}$ units of labor respectively. We combine all types of labor using a constant elasticity of substitution (CES) function

$$
H_{t}=B\left(\sum_{i} \gamma_{i}\left(H_{t}^{i}\right)^{1-\rho}\right)^{\frac{1}{1-\rho}} \text { with } \sum_{i \in \mathcal{H}} \gamma_{i}=1,
$$

where $B$ is the parameter that controls the overall efficiency of labor input, $\rho$ is the substitutability factor and $\gamma_{i}$ 's are the weights associated to each educational attainment level in the labor force.

We assume our representative firm maximizes the net cash flow by renting capital and hiring labor from households in competitive markets at the rates $r$ and $\omega_{t}^{i}$, respectively. The optimal choice by firms is characterized by the maximization of the present value of the stream of net cash flows $X_{t}$ :

$$
X_{t}=Y_{t}-\left(1+(1-\varsigma) \tau_{s, t}\right) \sum_{i} \omega_{t}^{i} H_{t}^{i}-I_{t}
$$


where $(1-\varsigma) \tau_{s t}$ reflects the fraction of the social contribution paid by the employer. Then capital and skill-specific labor inputs are chosen by firms according to the first-order conditions:

$$
\begin{aligned}
r+\delta & =\alpha\left(Y_{t} / K_{t}\right), \\
\left(1+(1-\varsigma) \tau_{s, t}\right) \omega_{t}^{i} & =(1-\alpha)\left(Y_{t} / H_{t}\right) \gamma_{i} B^{1-\rho}\left(H_{t}^{i} / H_{t}\right)^{-\rho}, \text { for } i \in \mathcal{H} .
\end{aligned}
$$

Notice that the skill premium can be obtained combining the effective wages in $\mathrm{Eq}(18)$ as

$$
\begin{aligned}
\omega_{t}^{m} / \omega_{t}^{l} & =\left(\gamma_{m} / \gamma_{l}\right)\left(H_{t}^{m} / H_{t}^{l}\right)^{-\rho} & \text { (medium-low), } \\
\omega_{t}^{h} / \omega_{t}^{l} & =\left(\gamma_{h} / \gamma_{l}\right)\left(H_{t}^{h} / H_{t}^{l}\right)^{-\rho} & \text { (high-low). }
\end{aligned}
$$

Hence, when $\rho=0$ and $\gamma_{l}=\gamma_{m}=\gamma_{h}$ all workers are considered perfectly substitutable. Instead, if $\rho>0$, an increase in the relative supply of skills, $H^{m} / H^{l}$ and $H^{h} / H^{l}$, reduces their skill premium.

\subsection{Government}

Each period the government provides public goods and services (e.g. health care, education), denoted by $G$, and retirement pension benefits. To finance $G$, the government levies taxes on labor income $\left(\tau_{l}\right)$, on capital income $\left(\tau_{k}\right)$, and on consumption $\left(\tau_{c t}\right)$. To guarantee that the budget of the government is balanced period by period, we assume that consumption taxes finance the gap between public consumption expenditures and capital and labor income tax revenues. Thus, the government budget constraint is

$$
G_{t}=\tau_{l}\left(1+(1-\varsigma) \tau_{s, t}\right) \sum_{i} \omega_{t}^{i} H_{t}^{i}+\tau_{k} r_{t} A_{t}+\tau_{c t} C_{t}
$$

where $C_{t}$ is the aggregate consumption in year $t$ and $A_{t}$ is the aggregate financial wealth in year $t$. Similarly, each period the government modifies the social security contribution rate $\tau_{s, t}$ so as to finance all retirement benefits claimed

$$
\tau_{s, t} \sum_{i} \omega_{t}^{i} H_{t}^{i}=\sum_{x} \sum_{i} b_{t, x}^{i} N_{t+1, x+1} \Upsilon_{t-x}(i) .
$$

In subsections 7.2-7.3, Eq (21) is relaxed in order to analyze two policies: i) the introduction of an unbalanced public pension system and ii) an introduction of a notional defined contribution system.

\section{Definition of equilibrium}

Let $z, x \in \mathcal{X}, t \in \mathcal{T}, i \in \mathcal{H}$. Given initial values $\left\{\delta, \alpha,\left\{\gamma_{i}\right\}_{i \in \mathcal{H}}, g, \Gamma_{0}\right\}$, demographics $\left\{N_{t, x}, \pi_{t, x}, \eta_{t, x}\right\}_{x \in \mathcal{X}, t \in \mathcal{T}}$, and the educational distribution $\Upsilon_{t}$, a recursive competitive equilibrium is a sequence of a set of household policy functions $\left\{c_{t-x, x}, l_{t-x, x}, a_{t-x, x}, P_{t-x, x}, z\right\}_{x \in \mathcal{X}, t \in \mathcal{T}}$, government policy functions $\left\{G_{t}, \tau_{c t}, \tau_{k t}, \tau_{l t}, \tau_{s t}, b_{t, x}\right\}_{t \in \mathcal{T}}$, and factor prices $\left\{\omega_{t}^{i}, r_{t}\right\}_{t \in \mathcal{T}}$ such that 
i) given the factor prices and government policy functions, household policy functions satisfy (4), (6), (8) and (12).

ii) factor prices equal their marginal productivities so that (17) and (18) hold.

iii) the government's budget constraints (20)-(21) are satisfied.

iv) the stock of capital and skill-specific effective labor input are given by:

$$
\begin{aligned}
K_{t} & =\sum_{i} \sum_{x \geq x_{0}} N_{t, x} a_{t, x}^{i} \Upsilon_{t-x}(i)-F_{t}, \\
H_{t}^{i} & =\sum_{x \geq x_{0}} \epsilon_{x}(i) l_{t, x} N_{t+1, x+1} \Upsilon_{t-x}(i), \text { for } i \in \mathcal{H},
\end{aligned}
$$

where $F_{t}$ is the value of internationally traded bonds.

v) the commodity market clears:

$$
Y_{t}+r F_{t}=C_{t}+G_{t}+S_{t},
$$

where $S_{t}$ is gross savings in year $t$.

\section{Data and calibration}

The aim of this paper is to understand the economic implications of changes in demographics, education and pension reforms on the Austrian economy. Our modeling strategy started from reconstructing the main demographic variables for Austria from 1871 up to now using demographic data from the Human Mortality Database, the Human Fertility Database, the Human Life Tables and Statistics Austria. From year 2010 onwards, our population forecast is based on the assumptions of UN Population Division for Austria (case: medium variant). Demographics will be considered exogenous to our model economy (see C.4 for further details). In a second step we built up a model economy and calibrate it to match the educational transition in Austria as well as several key economic time series. In Subsection 6.1, we calculate exogenous profiles of age specific efficiency units for each education group and the backcast and forecast of the educational distribution in Austria. In Subsection 6.2, we choose the model parameters that characterize our representative neoclassical firm. In Subsection 6.3 , we model the main government outlays and revenues, where we replicate in very much detail public education expenditures and retirement benefits. Finally in Subsection 6.4, we choose the parameters for the household heads.

\subsection{Age-specific productivity indexes and educational tran- sition}

We assume that workers are heterogenous by age and educational level. We calculate age-efficiency profiles for different educational groups using data from 
Income, Social Inclusion and Living Conditions (EU-SILC) data source for the year 2006, which contains 14.882 individuals. Having micro data on individuals' gross earnings per hour and highest educational level completed, we construct age profiles for three educational groups: primary education (ISCED levels 0-2), secondary education (ISCED levels 3-4) and tertiary education (ISCED levels 5-6), consistently with ILO division (see Figure 2(a)).

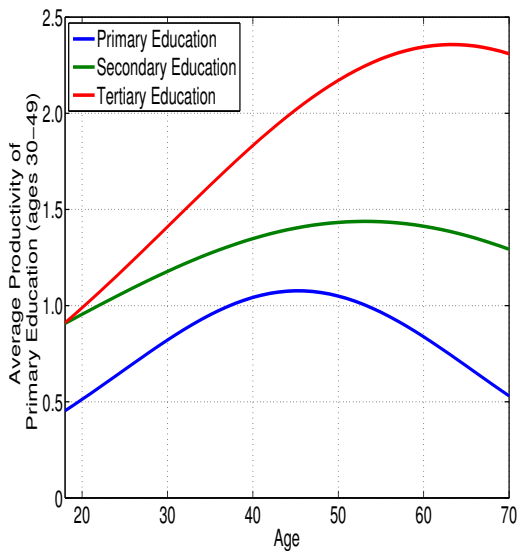

(a) Age-specific productivity, $\epsilon_{x}(i)$.

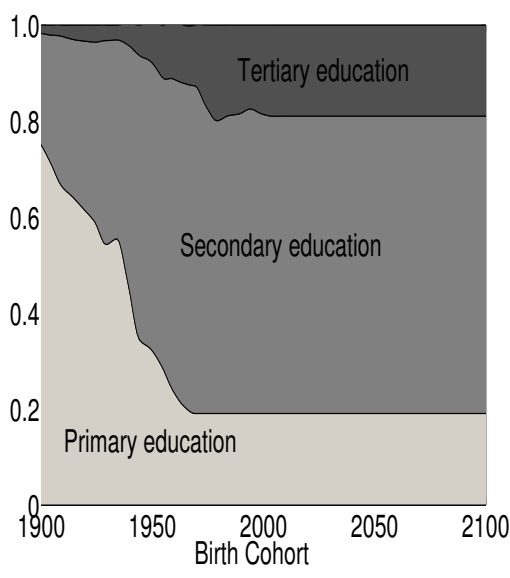

(b) Educational distribution, $\Upsilon_{t}(i)$.

Figure 2: Decomposition of the effective labor input

Source: Authors' estimations based on data from EU-SILC 2006, IPUMSInternational and Samir et al. (2010).

We take into account the educational transition in Austria combining data from IPUMS-International and Samir et al. (2010). Note that Samir et al. (2010) also use information from IPUMS-International and thus both data sources are completely compatible. In Figure 2(b) of the same figure we report the educational transition by birth cohort. In order to understand the impact of changes in the education level, in Section 7 we will assume an alternative forecast in the educational transition consisting on higher tertiary education rates.

\subsection{Firm}

Our choices for capital share, labor-augmenting productivity growth rate and depreciation of capital are $\alpha=.31, g=.01$ and $\delta=.04$, respectively, based on information from KLEMS database. Moreover, in our baseline case, we assume that the parameter that controls the overall efficiency of labor input is set to a normalized value of one, $B=1$. Since the capital-to-output ratio has been fairly constant from 1976 to 2005 in Austria, we assume a fixed interest rate of $3.75 \%$ based on an average capital-to-output ratio of 4 and an annual depreciation rate of .04. 
Given the lack of time series data for estimating individuals' gross earnings per hour, we cannot estimate the substitutability factor. Instead, we assume a $\rho$ value of 0.20 . Since the effect of changes in aggregate human capital depends on $\rho$, we run a sensitivity analysis with $\rho$ values of 0 and 0.6 , based on the recent work by Acemoglu and Autor (2012), in Subsection 7.4.

\subsection{Government revenues and outlays}

\subsubsection{Revenues}

Our government provides retirement benefits and public goods and services (e.g. education and others). To finance these expenditures we introduce a consumption $\operatorname{tax} \tau_{c}$, a labor income tax $\tau_{l}$, a capital income tax $\tau_{k}$, and social contributions $\tau_{s}$. It is important to keep in mind that there are differences between the Austrian government and our model economy. In Austria, the government also provides other social benefits like unemployment benefits, disability benefits, family allowances, parental-leave benefits, and childcare subsidies that are among the most generous family policy expenditures in OECD countries (Kalwij, 2010). These other governmental expenditures are partly financed by social contributions and partly by general taxes like consumption taxes and income taxes. In our model, we fixed the capital income tax to $13.7 \%$ and the labor income tax to $17.9 \%$, which correspond respectively to the average values of $\tau_{k}$ and $\tau_{l}$ for the period 1995-2007.

\subsubsection{Outlays}

Public consumption An important feature for analyzing the impact of population aging on economic growth is human capital investment, since more educated people have higher employment rates, higher productivity and longer working lives. To correctly model a change in the educational distribution, taking into account not only the benefits in the labor market but also its initial cost, we split public consumption into public education expenditures and other public consumptions (e.g. infraestructures, burocracy, defense, etc.). Let $G_{t}^{e}$ denote public education expenditures and $G_{t}^{n e}$ denote other public consumptions. Thus, aggregate public consumption is given by

$$
G_{t}=G_{t}^{n e}+G_{t}^{e}, \text { with } G_{t}^{n e}=g_{t}^{n e} Y_{t} .
$$

where $g_{t}^{n e}$ is the fraction of other public consumption to output in year $t$. Since the average public consumption to output ratio from year 1995 to 2007 was $21 \%$, we set the value of $g_{t}^{n e}$ at $16 \%$, which is the difference between the public consumption-output ratio and public education-output ratio in 2006 (the reference year of our estimated values of the education profiles).

Public education We calculate the cost of public education expenditures in two steps. First, we construct the cost of the public education by household as 
follows:

$$
\eta_{t, x}^{e}=\sum_{i \in \mathcal{H}} \theta_{x}^{i} \Upsilon_{t-x}(i)+\sum_{i \in \mathcal{H}} \sum_{u=x_{0}}^{x} \frac{S_{t-x, u} f_{t-x, u}}{S_{t-x, x}} S_{t-(x-u), x-u} \theta_{x-u}^{i} \Upsilon_{t-x+u}(i),
$$

where $\theta_{x}^{i}$ is the average cost of education at age $x$ per student in education $i \in \mathcal{H}$, see Figure 3, and $f_{s, x}$ is the fertility rate at age $x$ in year $s$. Values of $\theta_{x}^{i}$ are calculated from expenditures on public education per student reported by EUSILC 2006. The first term of Eq (26) is the education cost of the household head while the second term represents the total cost of education of the children living in the household. Second, we calculate aggregate public education expenditure in period $t$ by adding the cost of public education across household heads

$$
G_{t}^{e}=\bar{w}_{t} \sum_{x \geq x_{0}} \eta_{t, x}^{e} N_{t+1, x+1},
$$

where $\bar{w}_{t}$ is the average labor income in year $t$.

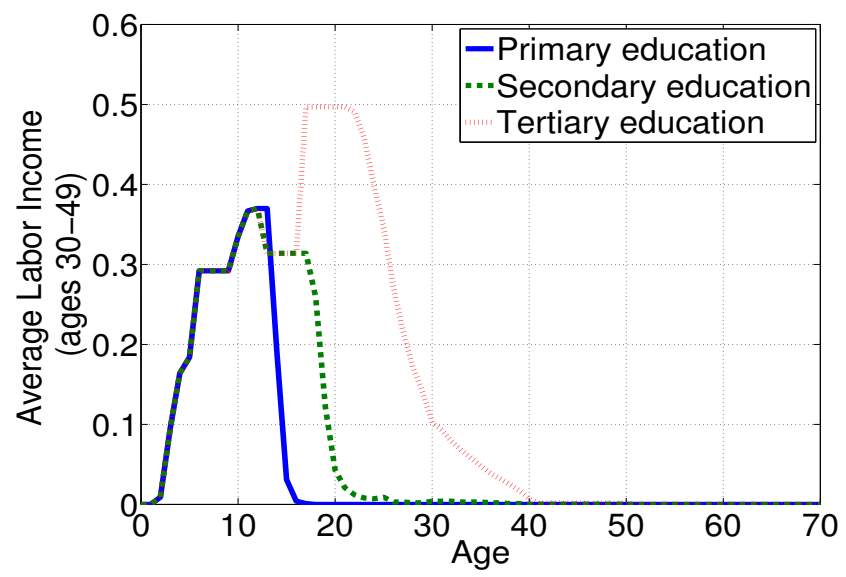

Figure 3: Average expenditure in public education by age and education level, $\theta_{x}^{i}$.

Source: EU-SILC 2006 and authors' calculations.

Retirement benefits Our model replicates the main features of the Austrian pension systems from year 2000 up to now. As in the Austrian pension system, we assume that workers can claim a retirement pension benefit when they reach an early retirement age. The retirement pension benefit that each retiree is entitled is proportional to her earnings until she claims benefits. We assume, yet realistically, that pensions can be bounded by a minimum pension. We model 
retirement benefits received from year $t$ according to the following formula:

$$
b(z)=\frac{\lambda \phi}{N_{b}} \sum_{u=\hat{z}-N_{b}}^{\hat{z}-1} \frac{y_{t+u-\hat{z}, u}^{i}}{\left(1-\tau_{l}\right)\left(1-\varsigma \tau_{s, t+u-\hat{z}}\right)}, \text { with } \hat{z}=\max \left(z, z_{e}\right),
$$

where $\lambda$ denotes the penalties and incentives for early and late retirement, $N_{b}$ is the number of years before retirement used to calculate the retirement benefit and $\phi$ is the replacement ratio of the pension benefit. The reform of each parametric component of the Austrian pension system is summarized in Table 1.

Table 1: Key parameters of the Austrian pension reforms in 2000, 2003 and 2004

\begin{tabular}{|c|c|c|c|c|}
\hline Parameter & Before 2000 & Reform 2000 & Reform 2003 & Reform 2004 \\
\hline $\begin{array}{l}\text { Normal retirement } \\
\text { age }\left(z_{n}\right)\end{array}$ & $65(\mathrm{~m}) / 60(\mathrm{f})$ & $65(\mathrm{~m}) / 60(\mathrm{f})$ & $65(\mathrm{~m}) / 60(\mathrm{f})$ & $\begin{array}{l}65(\mathrm{~m}) / \text { gradually to } \\
65(\mathrm{f}) \text { by } 2034\end{array}$ \\
\hline $\begin{array}{l}\text { Early retirement } \\
\text { age }\left(z_{e}\right)\end{array}$ & $60(\mathrm{~m}) / 55(\mathrm{f})$ & $\begin{array}{l}+0.5 \text { years per } \\
\text { annum; in } 2003 \\
61.5(\mathrm{~m}) / 56.5(\mathrm{f})\end{array}$ & $\begin{array}{l}\text { Both genders } \\
\text { gradually to } 62 \text { : } \\
2006(\mathrm{~m}) / 2028(\mathrm{f})\end{array}$ & $\begin{array}{l}\text { Both genders } \\
\text { gradually to } 62 \text { : } \\
2006(\mathrm{~m}) / 2028(\mathrm{f})\end{array}$ \\
\hline $\begin{array}{l}\text { Adjustment of } \\
\text { existing pensions }\end{array}$ & $\begin{array}{l}\text { De facto close to } \\
\text { CPI }\end{array}$ & $\begin{array}{l}\text { De facto close to } \\
\text { CPI }\end{array}$ & $\begin{array}{l}\text { De facto close to } \\
\text { CPI }\end{array}$ & $\begin{array}{l}\text { De iure close to } \\
\text { CPI }\end{array}$ \\
\hline $\begin{array}{l}\text { Assessment period } \\
\left(N_{b}\right)\end{array}$ & Best 15 years & Best 15 years & $\begin{array}{l}+1 \text { per annum to } \\
40 \text { best years in } \\
2028\end{array}$ & $\begin{array}{l}+1 \text { per annum also } \\
\text { after } 2028 \text { - to } \\
\text { lifetime earnings }\end{array}$ \\
\hline $\begin{array}{l}\text { Accrual rate per } \\
\text { year }\end{array}$ & $2 \%$ & $2 \%$ & $\begin{array}{l}\text { Gradually to } 1.78 \% \\
\text { in } 2009\end{array}$ & $\begin{array}{l}\text { Gradually to } 1.78 \% \\
\text { in } 2009\end{array}$ \\
\hline $\begin{array}{l}\text { Replacement rate } \\
\text { for full pension } \\
\text { qualifying period }\end{array}$ & $\begin{array}{l}80 \% \text { (for } 40 \text { years } \\
\text { of work); } 80 \% \text { is } \\
\text { also max }\end{array}$ & $\begin{array}{l}80 \% \text { (for } 40 \text { years } \\
\text { of work); } 80 \% \text { is } \\
\text { also } \max \end{array}$ & $\begin{array}{l}\text { From } 2009 \text { on } 80 \% \\
\text { (for } 45 \text { years of } \\
\text { work) }\end{array}$ & $\begin{array}{l}\text { From } 2009 \text { on } 80 \% \\
\text { (for } 45 \text { years of } \\
\text { work) }\end{array}$ \\
\hline $\begin{array}{l}\text { Penalization for } \\
\text { early retirement }\end{array}$ & - & $3 \%$ per annum & $4.2 \%$ per annum & $4.2 \%$ per annum \\
\hline $\begin{array}{l}\text { Reward for later } \\
\text { retirement }\end{array}$ & - & $\begin{array}{l}4 \% \text { per annum for } \\
\text { up to } 3 \text { years }\end{array}$ & $4.2 \%$ per annum & $4.2 \%$ per annum \\
\hline
\end{tabular}

Notes: Letters ' $\mathrm{m}$ ' and 'f' denote males and females respectively, while CPI stands for consumer price index.

\subsection{Households}

We characterize our households according to three parameters: subjective discount factor $(\beta)$, risk aversion coefficient $(\sigma)$, and the weight on consumption $(\phi)$. In the baseline model we set the subjective discount factor to one, leaving the survival probability as the only measure that discounts future preferences. 
This assumption follows many articles in the applied OLG literature such as Boucekkine et al. (2002) and Lee et al. (2000), among others. The risk aversion coefficient is set to 1.6 in order to approximate the financial wealth-to-output ratio with the observed capital-to-output ratio from 1976 to 2005. Recall the average capital-to-output ratio reported by KLEMS for the period 1976 to 2005 is 4. Moreover, this value of the risk aversion guarantees that Austria is a net capital investor overseas. The weight on consumption $\phi$ is chosen to yield an average hours worked equal to 0.36 by year 2000. Therefore, according to our baseline values of $\{\sigma, \phi\}$, our average Frisch labor supply elasticity is 1.2, which is within the range of values $0.2-1.5$ reported in the empirical literature at the macro and micro level (Keane, 2011; Keane and Rogerson, 2012), and our average intertemporal elasticity of substitution on consumption is 1.65 over the working life.

Table 2 summarizes the baseline model economy parameters.

Table 2: Model economy parameters

\begin{tabular}{lccc}
\hline \hline & Symbol & Value & Source \\
\cline { 2 - 3 } Household heads & & & \\
Risk aversion coefficient & $\sigma$ & 1.600 & \\
Weight on consumption & $\phi$ & 0.265 & \\
Subjective discount factor & $\beta$ & 1.000 & \\
Age at leaving parent's home & $x_{0}$ & 18 & \\
Employee social contribution share & $\zeta$ & 0.50 & KLEMS \\
& & & \\
Technology & & & \\
Capital share & $\alpha$ & 0.310 & KLEMS \\
Overall efficiency of labor & $B$ & 1.086 & KLEMS \\
Substitutability factor & $\rho$ & 0.200 & KLEMS \\
Weights on education & $\left\{\gamma_{l} ; \gamma_{m}\right\}$ & $\{0.3062 ; 0.3961\}$ & EU-SILC \\
Depreciation rate & $\delta$ & $4.00 \%$ & \\
Rental price of capital & $r$ & $3.75 \%$ & \\
Productivity growth & $g$ & $1.00 \%$ & IIASA \& IPUMS-International \\
Labor efficiency profile & $\epsilon_{x}(i)$ & & KLEMS \& OECD \\
Education distribution & $\Upsilon_{t}$ & & KLEMS \& OECD \\
Government & & & KLEMS \& OECD \\
Other public consumption to output & $g_{t}^{n e}$ & 0.160 & EU-SILC \\
Capital income tax rate & $\tau_{k}$ & 0.137 & \\
Labor income tax rate & $\tau_{l}$ & 0.179 & \\
Public education expenditure by age & $\theta_{x}^{i}$ & & \\
\hline & & & \\
\hline
\end{tabular}

\section{Results}

In the following we present results on simulations of various scenarios of our model. We start with the results of the 'baseline' scenario that assumes the status quo of the Austrian pension system. Next we simulate alternative pension policies and present the results always relative to this baseline scenario. First, we simulate the impact on macroeconomic variables if pension reforms in 2000, 2003 and 2004 would not be implemented (Subsection 7.1). We continue to 
discuss alternative pension systems. In Subsection 7.2, we present the results of introducing notional defined benefits (NDB) and notional defined contributions (NDC) pension system. Next, we test an alternative approach for financing the deficit of the pension system (Subsection 7.3) and, finally, we simulate the impact of increasing investments into human capital (Subsection 7.4).

\subsection{The economic impact of recent pension reforms}

The very low retirement age during the 1990s in combination with increasing longevity and low fertility was calling for changes in the Austrian pension system. Reforms in 2000, 2003 and 2004 were introduced to mitigate the expected rapid growth of pension outlays. Table 1 summarizes key parameters of these reforms.

To understand the role of these pensions reforms for the macroeconomic development, we run a scenario ('no pension reform' scenario) that assumes that the pension reforms in 2000, 2003 and 2004 would not have taken place. Since we have assumed a constant interest rate, the evolution of output and capital over time are determined by the labor supply. Therefore, the contribution of any pension reform to the economy rests on how the reform affects the effective labor supply. Table 3 indicates that without these pension reforms the effective labor supply in 2100 would be $13 \%$ lower compared to the baseline scenario that takes into account the pension reforms of 2000, 2003 and 2004 (column 4). The change in the effective labor supply is composed of both, the change at the extensive margin and the change at the intensive margin. At the extensive margin labor supply in the 'no pension reform' scenario is much lower as compared to the baseline scenario since people retire on average 6 years earlier (column 6 ). The reason for earlier retirement in the 'no pension reform' scenario is the higher internal rate of return (IRR) of the pension system around ages 57-58, while in the baseline scenario the IRR is higher around ages 62-63 (see figures 4(a) and $4(\mathrm{~b}))$. Figure 4 depicts the IRR of the pension system in each scenario. Different colors in Figure 4 plot different levels of IRR (i.e. contours). The horizontal axis gives the age at which individuals retire, while the vertical axis denotes the year at which they retire. The maximum values of the IRR for each retirement year are connected with a dashed-black line.

In comparison to the labor supply at the extensive margin, the labor supply on the intensive margin depends on several factors. First, it will be determined by the effective tax on hours worked. The higher is the effective tax the lower is the marginal rate of substitution between leisure and consumption (see Eq $31 \mathrm{~b}$ ) and consequently individuals work less intensively. Each panel of Figure 5 shows the effective tax on hours worked. Age is represented in the horizontal axis, while the calendar year is depicted in the vertical axis. Different levels of the effective tax on hours worked are represented by different colors in Figure 5. Note that the effective tax on hours worked in the 'no pension reform' scenario (Figure 5(b)) is higher than in the baseline scenario (Figure 5(a)). The second factor influencing the labor supply at the intensive margin is the retirement age. Because in the 'no pension reform' scenario individuals retire much earlier than 
in the baseline scenario, workers try to compensate the negative income effect by working more intensively. Finally, since our work intensity profile is humpshaped, people with longer labor histories have lower average work intensity. All three factors combined result in a higher work effort in the 'no pension reform' scenario compared to the baseline scenario (see column 5 in Table 3).

Since the size and distribution of the population is the same in both scenarios, the total effect on the labor supply translates in the same drop in output per capita. From 2020 onwards output per capita is between 10 to $15 \%$ lower in the "no pension reform scenario as compared to the baseline scenario. Together, a lower value of output per capita, a lower retirement age and higher pension benefits in 2020-2100 imply that the pension to output ratio is about 40-60\% higher as compared to the baseline scenario (column 9 in Table 3). To finance higher pension expenditures the social contribution rate has to increase sharply. Already by year 2030 the social contribution rate is $76 \%$ higher than in the baseline scenario (column 7). The increasing social contribution rate is the main driver of the future decrease in the IRR presented in Figure 4(b). On the contrary, the decline in the IRR in the baseline scenario (see Figure 4(a)) is mainly due to the decrease in benefits implied by the pension reforms in 2000 , 2003, and 2004.

Increasing social contribution rate lowers the disposable income and consequently consumption. Under the 'no pension reform' scenario the higher crowding-out effect of savings due to the higher social contribution rate results in a lower financial wealth to output ratio compared to the baseline scenario. As a consequence, in order to balance public revenues with public outlays even higher increase in the indirect tax rate is required (column 8 in Table 3).

\subsection{Implementation of alternative pension systems}

In this subsection we implement two alternative notional pension systems for cohorts born after the year 1955: i) notional defined pension system (NDB), and ii) notional defined contribution system (NDC). The basic principal of a notional pension system is that it mimics a funded pension system without actually setting aside assets (Auerbach and Lee, 2006; Holzmann and Palmer, 2006). In both pension systems, we assume that social contributions are capitalized according to the (net) interest rate from private markets (see figures 4(c) and 4(d)). Recalling Proposition 1 we know that in this case, there is no effective social contribution tax. As a consequence, under both pension reforms, the effective tax on hours worked is only a function of the labor income tax, which is considered fixed and equal to $17.9 \%$, and the consumption tax rate; i.e. $t^{E}=1-\left(1-\tau_{l}\right) /\left(1+\tau_{c}\right){ }^{3}$ Figures $5(\mathrm{c})$ and $5(\mathrm{~d})$ show the effective tax on

\footnotetext{
${ }^{3}$ In both notional pension systems (defined benefit and defined contribution), we have assumed that the internal rate of return equals the capital market interest rate (net of capital income tax). As a consequence, neither of the two notional pension systems modeled raise the effective social contribution tax. However, many of the notional pension systems implemented in countries like Sweden, Italy, or Germany assume an underlying internal rate of return that is close to the growth rate of wages, which, in general, are lower than the market interest rate.
} 
Table 3: Economic impact of the pension reforms

\begin{tabular}{|c|c|c|c|c|c|c|c|c|c|c|c|}
\hline Year & $\begin{array}{r}\text { Output } \\
\text { per } \\
\text { capita }\end{array}$ & $\begin{array}{r}\text { Consum. } \\
\text { per } \\
\text { capita }\end{array}$ & $\begin{array}{r}\text { Effec. } \\
\text { labor } \\
\text { supply }\end{array}$ & $\begin{array}{l}\text { Aver. } \\
\text { work } \\
\text { effort }\end{array}$ & $\begin{array}{r}\text { Aver. } \\
\text { retire. } \\
\text { age }\end{array}$ & $\begin{array}{r}\text { Social } \\
\text { secur. } \\
\text { tax }\end{array}$ & $\begin{array}{r}\text { Indirect } \\
\text { tax }\end{array}$ & $\begin{array}{r}\text { Pension } \\
\text { to } \\
\text { output }\end{array}$ & $\begin{array}{r}\text { Benefit } \\
\text { ratio }\end{array}$ & $\begin{array}{r}\text { Educ. } \\
\text { to } \\
\text { output }\end{array}$ & $\begin{array}{r}\text { Wealth } \\
\text { to } \\
\text { output }\end{array}$ \\
\hline & II & III & IV & V & VI & VII & VIII & IX & $\mathrm{X}$ & XI & XII \\
\hline \multicolumn{12}{|c|}{ Baseline } \\
\hline 2000 & 100.0 & 100.0 & 100.0 & 0.36 & 57.1 & 0.25 & 0.10 & 0.15 & 0.46 & 0.04 & 4.0 \\
\hline 2005 & 111.6 & 108.2 & 107.3 & 0.36 & 59.1 & 0.23 & 0.10 & 0.14 & 0.48 & 0.04 & 3.9 \\
\hline 2010 & 122.3 & 115.6 & 113.6 & 0.36 & 60.7 & 0.22 & 0.10 & 0.14 & 0.48 & 0.04 & 3.9 \\
\hline 2020 & 131.2 & 133.3 & 110.1 & 0.35 & 60.1 & 0.27 & 0.08 & 0.17 & 0.50 & 0.04 & 4.6 \\
\hline 2030 & 134.2 & 151.9 & 101.8 & 0.34 & 62.0 & 0.35 & 0.07 & 0.20 & 0.55 & 0.04 & 5.2 \\
\hline 2040 & 141.5 & 170.0 & 95.6 & 0.34 & 62.2 & 0.40 & 0.07 & 0.23 & 0.55 & 0.04 & 5.1 \\
\hline 2050 & 156.2 & 186.4 & 92.8 & 0.34 & 62.4 & 0.40 & 0.07 & 0.23 & 0.53 & 0.04 & 4.6 \\
\hline 2060 & 168.3 & 199.7 & 84.9 & 0.35 & 62.4 & 0.42 & 0.08 & 0.24 & 0.53 & 0.04 & 4.2 \\
\hline 2070 & 195.3 & 214.2 & 82.7 & 0.36 & 62.8 & 0.39 & 0.09 & 0.22 & 0.51 & 0.04 & 3.6 \\
\hline 2080 & 220.4 & 231.6 & 78.8 & 0.36 & 62.8 & 0.37 & 0.10 & 0.22 & 0.51 & 0.04 & 3.3 \\
\hline 2090 & 244.4 & 251.3 & 74.0 & 0.36 & 62.8 & 0.37 & 0.10 & 0.22 & 0.52 & 0.04 & 3.3 \\
\hline 2100 & 273.9 & 276.6 & 70.5 & 0.36 & 63.2 & 0.36 & 0.10 & 0.21 & 0.54 & 0.04 & 3.3 \\
\hline \multicolumn{12}{|c|}{$\begin{array}{l}\text { No pension reform } \\
\text { (\% change with respect to the Baseline) }\end{array}$} \\
\hline 2000 & 0.0 & 0.0 & 0.0 & 4.3 & 0.0 & -5.0 & 3.2 & -2.2 & -2.4 & 0.6 & -0.7 \\
\hline 2005 & -4.6 & -0.7 & -4.6 & 4.5 & -2.0 & 19.7 & -1.4 & 18.9 & 6.5 & 2.6 & 5.1 \\
\hline 2010 & -8.1 & -1.5 & -8.1 & 4.7 & -3.7 & 41.0 & -4.5 & 37.5 & 13.3 & 4.2 & 8.7 \\
\hline 2020 & -10.4 & -3.1 & -10.4 & 4.0 & -3.1 & 58.7 & -5.8 & 48.4 & 23.5 & 2.7 & 5.5 \\
\hline 2030 & -15.6 & -5.1 & -15.6 & 4.1 & -5.0 & 76.3 & -6.0 & 60.0 & 22.9 & 4.8 & 1.2 \\
\hline 2040 & -11.4 & -7.1 & -11.4 & 8.5 & -5.2 & 56.1 & 8.4 & 44.4 & 14.0 & 5.6 & -11.5 \\
\hline 2050 & -11.9 & -9.6 & -11.9 & 9.5 & -5.4 & 56.5 & 13.8 & 44.6 & 12.3 & 6.8 & -18.8 \\
\hline 2060 & -11.1 & -12.4 & -11.1 & 9.7 & -5.4 & 53.7 & 20.2 & 41.8 & 12.3 & 6.2 & -28.1 \\
\hline 2070 & -13.1 & -14.8 & -13.1 & 8.0 & -5.8 & 62.4 & 19.6 & 50.8 & 19.2 & 5.7 & -33.6 \\
\hline 2080 & -14.1 & -16.1 & -14.1 & 7.2 & -5.8 & 69.9 & 20.1 & 55.6 & 21.9 & 5.3 & -38.1 \\
\hline 2090 & -13.7 & -16.9 & -13.7 & 7.3 & -5.8 & 69.5 & 22.5 & 54.4 & 21.2 & 4.9 & -42.6 \\
\hline 2100 & -13.2 & -17.3 & -13.2 & 8.1 & -6.2 & 67.3 & 24.9 & 54.6 & 18.8 & 5.5 & -44.9 \\
\hline
\end{tabular}

Note: Differences in the average retirement age (column 6) between the Baseline and No Reform experiments are in absolute values. 


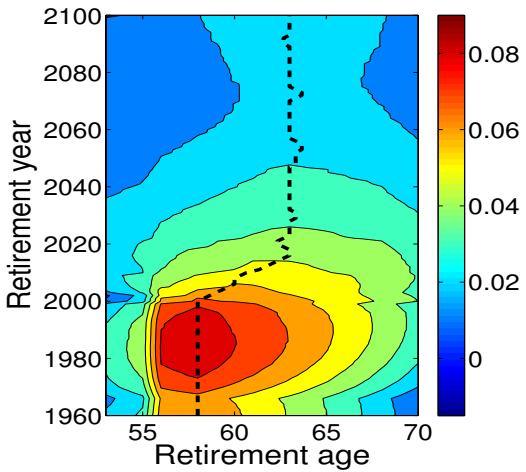

(a) Baseline

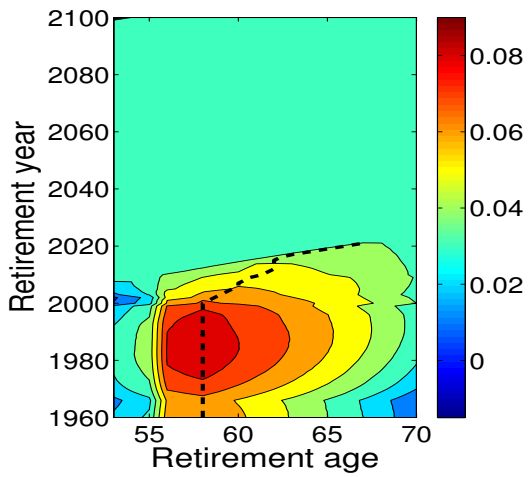

(c) Notional defined benefit

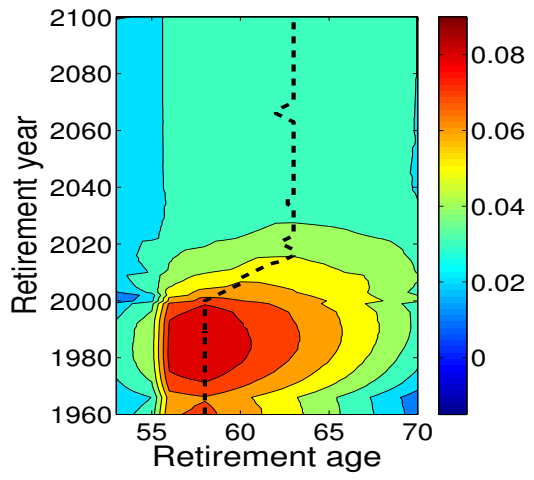

(e) Unbalanced

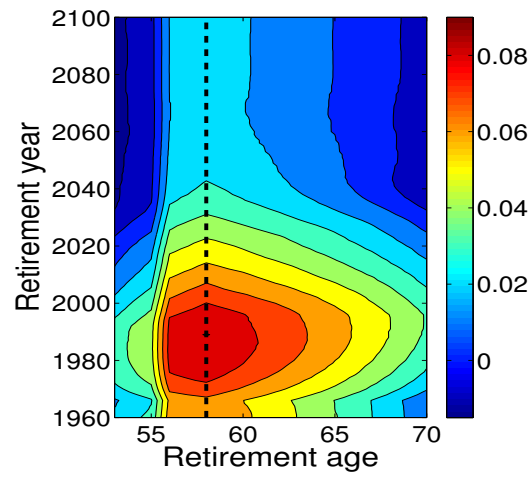

(b) No reform

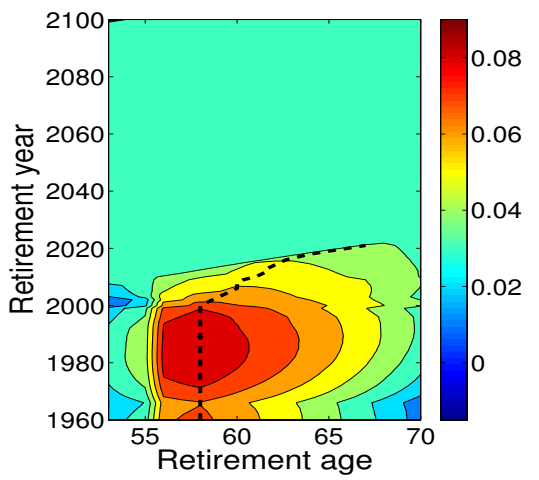

(d) Notional defined contribution

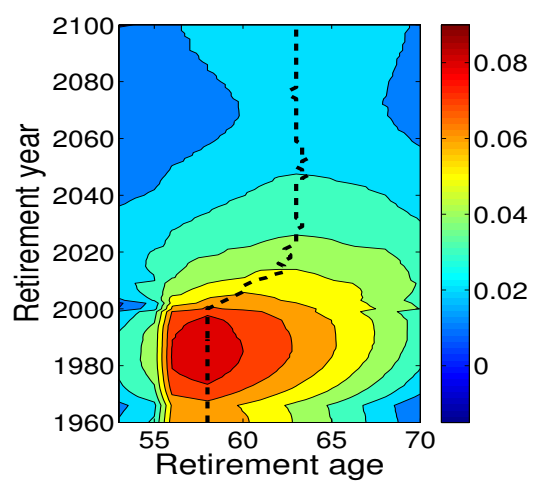

(f) Human capital

Figure 4: Contour plot: Average internal rates of return of the Austrian public pension system by retirement age and retirement year

Note: Dashed-black lines represent the maximum internal rate of return for each retirement year. 


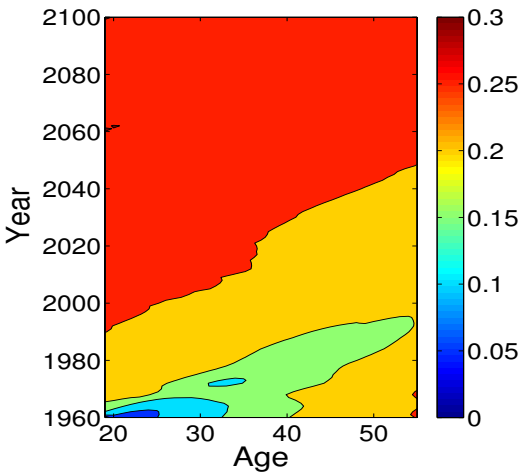

(a) Baseline

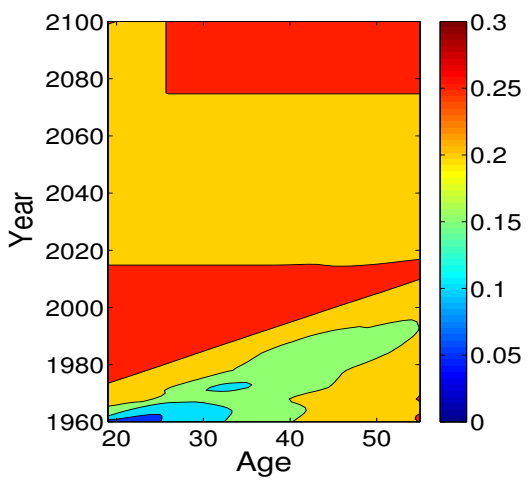

(c) Notional defined benefit

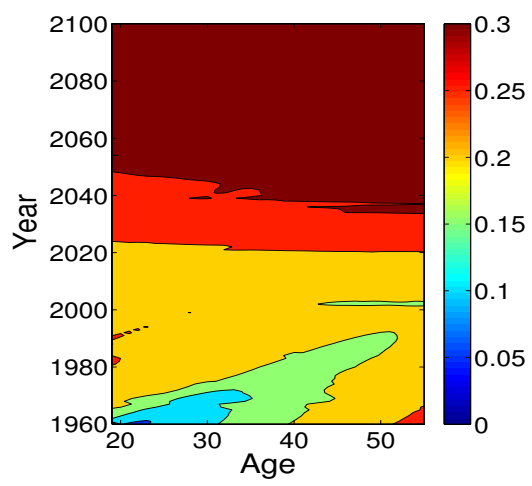

(e) Unbalanced

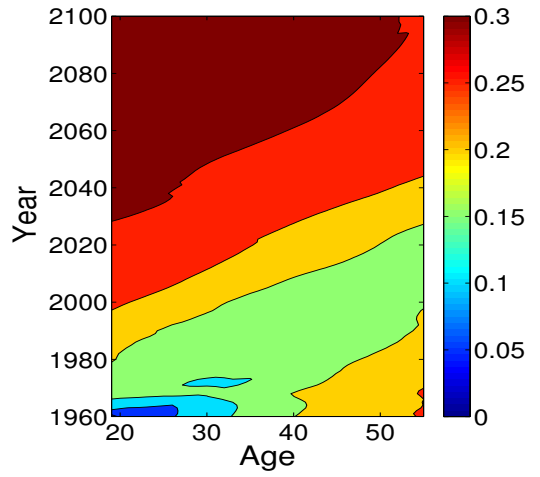

(b) No reform

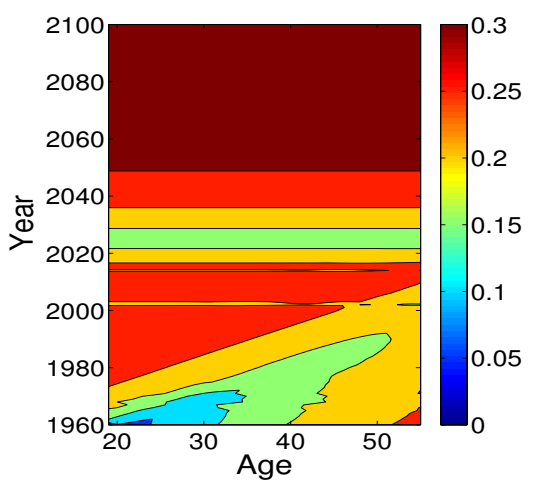

(d) Notional defined contribution

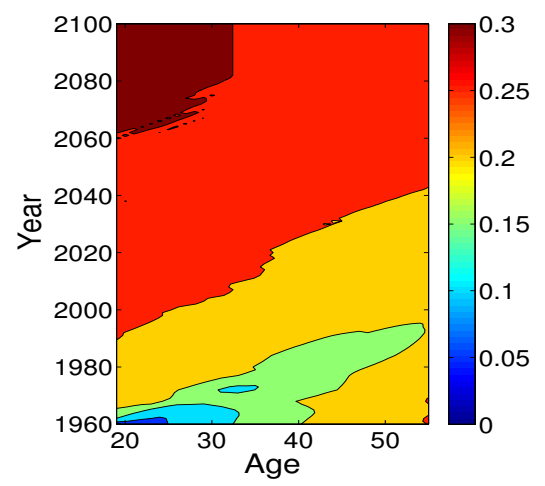

(f) Human capital

Figure 5: Contour plot: Average effective tax on hours worked by age and year, Austria 
hours worked for NDB and NDC, respectively. The implementation of the NDB system results in about a 2-4\% higher work effort from 2030 onwards compared to the baseline scenario (cf. Table 4, column 5) due to the lower effective tax on hours worked for cohorts born after the year 1955 (see Figure 5(c)). However, the retirement age does not significantly differ from the baseline scenario. ${ }^{4}$ Thus, the combination of a higher work effort and an unchanged retirement age results in an increase in effective labor supply, and consequently an increase in output of 3 to $5 \%$ compared to the baseline scenario during the period 2020-2100 (Table 4, columns 4 and 2). The development of other macroeconomic variables is close to the results of the baseline scenario. Thus, the NDB has a small, but positive, impact on economic outcome compared to the baseline scenario.

The NDC pension system brings much greater changes to the economy. In this scenario, we assume that the social contribution rate is fixed at $22.8 \%$ from year 2005 onwards, that coincides with the actual average social contribution rate paid in the year 2005. As a consequence, pension claims eventually exceed total contributions paid and the difference is financed through indirect taxes. ${ }^{5}$ As indicated in column 6, Table 4, the introduction of a NDC pension system from 2005 onwards results in a huge increase in labor supply at the extensive margin. From year 2020 onwards individuals retire 5 to 7 years later than in the baseline scenario. The increase in the retirement ages can be explained by the fact that the pension system is not perceived as a tax and hence the incentive for early retirement age vanishes (Gruber and Wise, 1999, 2004, 2007). In contrast, the average intensive labor supply decreases since firstly individuals have longer working careers and secondly because individuals face higher indirect taxes that need to be raised by the government to finance the pension system. This latter tax increase will increase the effective tax on hours worked (see Figure 5(d)). The net effect of these changes in labor supply at the extensive and the intensive margin is positive (cf. column 4 in Table 4), indicating that the positive impact of a later retirement age dominates. The difference in retirement age between the NDC scenario and the baseline scenario decreases from its maximum of about 6.8 years in 2030 to about 5 years in 2100 . Consequently also the positive difference in effective labor supply and output per capita decreases from about $16 \%$ in 2030 to about $6 \%$ in 2100 .

Due to the sharp increase in retirement age of 7 years already by year 2030 the pension to output ratio decrease by $40 \%$ compared to the baseline scenario (column 9 in Table 4). During this period not only the social contribution tax rate is lower (by being held constant at $22.8 \%$ of gross wages), but also the

Therefore, according to Proposition 1 these pension systems may also negatively affect the labor supply at the intensive and the extensive margins.

${ }^{4}$ Due to the technical fact that the retirement age is an integer and each cohort is comprised of three different labor skills, we may observe fluctuations in the average retirement age of \pm 1 year around the true optimal retirement values.

${ }^{5}$ It is worth mentioning that our results will to a large extend depend on the assumption that gaps between pension claims and total contributions are only financed through indirect taxes and not through other general taxes such as capital income tax and labor income tax. If capital income tax and labor income tax were increased, a lower wealth-to-output ratio and a lower effective labor supply would result. 
Table 4: Economic impact of a notional pension system

\begin{tabular}{|c|c|c|c|c|c|c|c|c|c|c|c|}
\hline Year & $\begin{array}{r}\text { Output } \\
\text { per } \\
\text { capita }\end{array}$ & $\begin{array}{r}\text { Consum. } \\
\text { per } \\
\text { capita }\end{array}$ & $\begin{array}{r}\text { Effec. } \\
\text { labor } \\
\text { supply }\end{array}$ & $\begin{array}{l}\text { Aver. } \\
\text { work } \\
\text { effort }\end{array}$ & $\begin{array}{r}\text { Aver. } \\
\text { retire. } \\
\text { age }\end{array}$ & $\begin{array}{r}\text { Social } \\
\text { secur. } \\
\text { tax }\end{array}$ & $\begin{array}{r}\text { Indirect } \\
\operatorname{tax}\end{array}$ & $\begin{array}{r}\text { Pension } \\
\text { to } \\
\text { output }\end{array}$ & $\begin{array}{r}\text { Benefit } \\
\text { ratio }\end{array}$ & $\begin{array}{r}\text { Educ. } \\
\text { to } \\
\text { output }\end{array}$ & $\begin{array}{r}\text { Wealth } \\
\text { to } \\
\text { output }\end{array}$ \\
\hline & II & III & IV & $\mathrm{V}$ & VI & VII & VIII & IX & $\mathrm{X}$ & XI & XII \\
\hline \multicolumn{12}{|c|}{$\begin{array}{l}\text { Notional defined benefit system } \\
\text { (\% change with respect to the Baseline) }\end{array}$} \\
\hline 2000 & 0.0 & 0.0 & 0.0 & -1.5 & 0.0 & 0.6 & -1.0 & 1.6 & 1.8 & -0.1 & 0.3 \\
\hline 2005 & 0.6 & 0.0 & 0.6 & -0.8 & 0.0 & 0.4 & -0.1 & 1.0 & 1.1 & 0.0 & -0.7 \\
\hline 2010 & 1.2 & 0.1 & 1.2 & -0.3 & 0.0 & 0.2 & 0.7 & 0.2 & 0.2 & 0.0 & -1.4 \\
\hline 2020 & 3.3 & 0.5 & 3.3 & 0.0 & 0.6 & -0.8 & 2.2 & -2.7 & 1.8 & -1.6 & -3.1 \\
\hline 2030 & 3.5 & 0.8 & 3.5 & 2.1 & 0.0 & -0.8 & 3.5 & -1.8 & -2.1 & 0.1 & -2.7 \\
\hline 2040 & 4.7 & 1.2 & 4.7 & 3.5 & 0.0 & -1.3 & 4.2 & -3.0 & -3.5 & 0.2 & -2.6 \\
\hline 2050 & 4.9 & 1.8 & 4.9 & 3.5 & 0.0 & -0.9 & 2.6 & -2.6 & -3.0 & 0.1 & -1.1 \\
\hline 2060 & 5.2 & 2.6 & 5.2 & 3.9 & 0.0 & -0.7 & 1.4 & -2.3 & -2.7 & 0.1 & 0.5 \\
\hline 2070 & 3.5 & 3.2 & 3.5 & 2.9 & -0.2 & 0.2 & -1.4 & 1.5 & 0.6 & 0.5 & 3.6 \\
\hline 2080 & 3.8 & 3.7 & 3.8 & 2.5 & 0.0 & -0.2 & -1.7 & -0.2 & -0.2 & 0.0 & 3.7 \\
\hline 2090 & 3.8 & 3.8 & 3.8 & 2.4 & 0.0 & 0.0 & -1.9 & 0.0 & 0.0 & 0.0 & 3.4 \\
\hline 2100 & 3.3 & 3.7 & 3.3 & 2.9 & -0.4 & 0.2 & -1.5 & 1.7 & -0.5 & 1.0 & 3.1 \\
\hline \multicolumn{12}{|c|}{$\begin{array}{l}\text { Notional defined contribution system } \\
\text { (\% change with respect to the Baseline) }\end{array}$} \\
\hline 2000 & 0.0 & 0.0 & 0.0 & -3.0 & 0.0 & 0.7 & 3.2 & 3.1 & 3.6 & -0.1 & 2.4 \\
\hline 2005 & 0.3 & -0.5 & 0.3 & -2.7 & 0.0 & -3.4 & 14.1 & 2.8 & 3.1 & 0.4 & -0.3 \\
\hline 2010 & -1.0 & 0.6 & -1.0 & -2.7 & -0.6 & 0.6 & 12.8 & 7.3 & 4.0 & 1.2 & -1.0 \\
\hline 2020 & 10.3 & 7.2 & 10.3 & -7.3 & 5.9 & -16.3 & -58.3 & -31.8 & 1.6 & -11.0 & -16.0 \\
\hline 2030 & 15.7 & 7.1 & 15.7 & -8.2 & 6.8 & -34.8 & -35.4 & -39.9 & 0.4 & -12.7 & -21.3 \\
\hline 2040 & 13.2 & 0.3 & 13.2 & -6.1 & 6.1 & -42.8 & 115.9 & -19.0 & 15.5 & -7.0 & -15.1 \\
\hline 2050 & 10.8 & -0.3 & 10.8 & -7.8 & 5.9 & -43.1 & 148.6 & -10.1 & 28.1 & -6.7 & -6.8 \\
\hline 2060 & 11.5 & 0.8 & 11.5 & -8.2 & 5.9 & -45.7 & 151.4 & -9.3 & 31.8 & -7.0 & 0.9 \\
\hline 2070 & 6.6 & 2.4 & 6.6 & -9.6 & 5.5 & -40.9 & 128.1 & -0.5 & 38.8 & -6.1 & 13.5 \\
\hline 2080 & 6.2 & 4.8 & 6.2 & -9.5 & 5.5 & -38.7 & 102.7 & -2.6 & 34.6 & -6.1 & 16.6 \\
\hline 2090 & 7.1 & 6.2 & 7.1 & -9.2 & 5.5 & -38.6 & 85.6 & -6.9 & 30.1 & -6.6 & 15.2 \\
\hline 2100 & 6.3 & 6.2 & 6.3 & -8.3 & 5.0 & -37.5 & 82.4 & -5.2 & 27.6 & -5.0 & 14.4 \\
\hline
\end{tabular}

Note: Differences in the average retirement age (column 6) between the Baseline and each notional pension system scenario are in absolute values. 
indirect taxes are lower as compared to the baseline scenario. After year 2030 however, the number of new entrants into retirement normalizes again (earlier it was low because of rapidly increasing retirement age) and consequently indirect taxes have to be increased sharply to allow a balanced pension system.

Since the time spent in retirement sharply decreases, lower financial wealth is sufficient for sustaining consumption during the retirement period. Consequently, financial wealth to output ratio decreases until 2050. From year 2060 onwards the positive impact of lower social contributions rates on saving dominates and the wealth to output ratio increases as compared to the baseline scenario.

Under the NDB system pension benefits are about the same as in the baseline scenario, but under the NDC system they are substantially higher (column 10 in Table 4). In both systems pension benefits are calculated using Eq (4) recursively from age $\Omega-1$ until $z$, which gives:

$$
b(z)=P_{t, z} / \sum_{s=z}^{\Omega-1}\left(\prod_{p=z}^{s} \frac{\pi_{t-z+p, p}}{1+\bar{r}}\right),
$$

where $\pi_{t, x}$ is the conditional survival probability at age $x$ in year $t$. However, since the retirement age in the NDC is higher compared to the NDB, individuals enjoy higher pension benefits because they have higher social security wealth at retirement $\left(P_{t, z}\right)$ and a shorter life span (from the retirement age on). This also explains why the pension to output ratio recovers from $-40 \%$ in year 2030 back to the levels from the baseline scenario. There are fewer retirees but they receive substantially higher pensions. As a result, in the NDC system total pension outlays are $5 \%$ below the baseline scenario by year 2100 (column 9 in Table 4).

\subsection{Unbalanced public pension budget}

In all scenarios we presented so far, we postulate a balanced pension system, i.e. outlays and revenues of the pension system are equal in each period. We achieve such a balanced pension system through adjusting social contribution rates correspondingly in a period-by-period manner. In reality this is not neces-

sarily the case. Indeed, the Austrian pension system is substantially subsidized from the general government budget, since pension contributions fall short of pension benefits.

To better mimic the Austrian situation we provide a scenario where we allow for an unbalanced pension system. We keep (similar to the NDC) the social contribution rate fixed at the level from year 2005 (22.8\% of gross wage) and allow pension expenditures to grow as induced by population aging. The increasing gap between pension outlays and revenues is covered through indirect taxes, i.e. through the general government budget.

Allowing for an unbalanced pension system does not change the effective labor supply significantly. Up to 2100 , the increase in the effective tax on hours worked (see figures $5(\mathrm{a})$ and $5(\mathrm{e}))$ - as compared to the baseline scenario - 
results in a lower intensive labor supply (column 4 in Table 5). Since the IRR stays almost the same and therefore does not change the incentives to retire (see the black-dashed line in figures $4(\mathrm{a})$ and $4(\mathrm{e})$ ), the extensive labor supply stays almost the same.

Table 5: Economic impact of fixing the contribution rate at $22.8 \%$ from year 2005

\begin{tabular}{|c|c|c|c|c|c|c|c|c|c|c|c|}
\hline Year & $\begin{array}{r}\text { Output } \\
\text { per } \\
\text { capita }\end{array}$ & $\begin{array}{r}\text { Consum. } \\
\text { per } \\
\text { capita }\end{array}$ & $\begin{array}{l}\text { Effec. } \\
\text { labor } \\
\text { supply }\end{array}$ & $\begin{array}{l}\text { Aver. } \\
\text { work } \\
\text { effort }\end{array}$ & $\begin{array}{r}\text { Aver. } \\
\text { retire. } \\
\text { age }\end{array}$ & $\begin{array}{r}\text { Social } \\
\text { secur. } \\
\text { tax }\end{array}$ & $\begin{array}{r}\text { Indirect } \\
\operatorname{tax}\end{array}$ & $\begin{array}{r}\text { Pension } \\
\text { to } \\
\text { output }\end{array}$ & $\begin{array}{r}\text { Benefit } \\
\text { ratio }\end{array}$ & $\begin{array}{r}\text { Educ. } \\
\text { to } \\
\text { output }\end{array}$ & $\begin{array}{r}\text { Wealth } \\
\text { to } \\
\text { output }\end{array}$ \\
\hline & II & III & IV & V & VI & VII & VIII & IX & $\mathrm{X}$ & XI & XII \\
\hline \multicolumn{12}{|c|}{$\begin{array}{l}\text { Unbalanced pension system } \\
\text { (\% change with respect to the Baseline) }\end{array}$} \\
\hline 2000 & 0.0 & 0.0 & 0.0 & 0.0 & 0.0 & 0.7 & -2.3 & 0.1 & 0.2 & -0.1 & 1.4 \\
\hline 2005 & -0.1 & -0.6 & -0.1 & -0.3 & 0.1 & -3.4 & 7.7 & -0.3 & 0.0 & 0.2 & 0.4 \\
\hline 2010 & -1.7 & 0.5 & -1.7 & -0.4 & -0.6 & 0.6 & 8.1 & 5.2 & 1.7 & 1.2 & 1.2 \\
\hline 2020 & 0.9 & -1.6 & 0.9 & -1.0 & 0.6 & -16.3 & 51.3 & -1.6 & 3.2 & 0.2 & -4.8 \\
\hline 2030 & 3.3 & -3.4 & 3.3 & 2.1 & 0.2 & -34.8 & 142.1 & -4.4 & -3.2 & 4.7 & -6.7 \\
\hline 2040 & 3.4 & -5.3 & 3.4 & 2.9 & 0.2 & -42.8 & 208.2 & -1.3 & -0.6 & 7.2 & 0.2 \\
\hline 2050 & 2.5 & -4.6 & 2.5 & 0.4 & 0.8 & -43.1 & 192.7 & -0.5 & 4.3 & 5.6 & 8.9 \\
\hline 2060 & 1.2 & -4.2 & 1.2 & 1.0 & 0.2 & -45.7 & 213.4 & 5.2 & 7.3 & 8.1 & 20.2 \\
\hline 2070 & -1.9 & -2.0 & -1.9 & -1.4 & 0.0 & -40.9 & 167.0 & 10.6 & 12.6 & 7.1 & 33.2 \\
\hline 2080 & -2.8 & 0.5 & -2.8 & -1.6 & -0.2 & -38.7 & 147.6 & 11.4 & 12.3 & 7.0 & 37.5 \\
\hline 2090 & -1.3 & 1.1 & -1.3 & -1.5 & 0.2 & -38.6 & 128.1 & 5.7 & 7.9 & 5.9 & 34.5 \\
\hline 2100 & -1.6 & 1.6 & -1.6 & -0.8 & -0.2 & -37.5 & 122.1 & 6.9 & 6.6 & 6.9 & 32.5 \\
\hline
\end{tabular}

Note: Differences in the average retirement age (column 6) between the Baseline and the unbalanced pension system scenario are in absolute values.

Social contributions gradually decline fluctuating at around a value of $40 \%$ lower level (column 7 in Table 5) as compared to the baseline scenario. Since the pension formula does not change, the lower value of social contributions that has to be paid results in an increase in the IRR (see Figure 4(e)). In addition, given that the intensive and extensive labor supplies are about the same as compared to the baseline scenario, the higher IRR (see Figure 4(e)) leads to a higher pension-to-output ratio and also to a higher benefit ratio (columns 9 and 10 in Table 5). To cover increasing pension outlays, indirect taxes rise (see column 8) up to $208 \%$ higher by 2040 as compared to the baseline scenario.

The lower taxation of labor income (compared to the increase in consumption taxes) stimulates savings, resulting in a ratio of financial wealth to output that is about one third higher from 2070 onwards compared to the baseline scenario.

\subsection{Human capital investment and workers substitutabil- ity}

In this subsection, we study a scenario where we postulate an increase in human capital. The motivation to introduce such a scenario is twofold. First, more 
educated people are more productive and, on average, work longer. Second, since current pension benefits are adjusted every year by inflation but not by productivity growth, policies that temporarily boost productivity may help to reduce contribution rates and may promote economic growth in the medium run.

According to Eurostat, in Austria the share of tertiary education among people between ages 25-34 was $20.8 \%$ in 2010, 13 percentage points below the average of the European Union ( 25 countries). To investigate the effect of higher educational investment we introduce a policy that progressively increases the educational attainment for cohorts born between 1995 and 2010 up to educational shares similar to other European countries like Ireland, Sweden and Switzerland, see Figure 6.

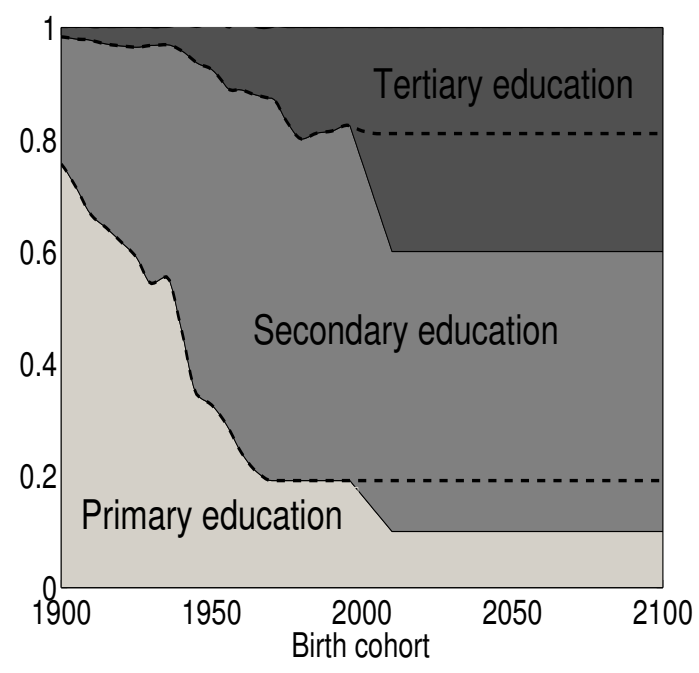

Figure 6: Educational distribution, $\Upsilon_{t}(i)$

Note: Dashed-black lines represent the baseline educational distribution plotted in Figure $2(\mathrm{~b})$.

Since human capital affects economic growth through labor, in what follows we explain how changes in the educational distribution modifies the effective labor supply. For a given demography, an increase in human capital affects the effective labor supply through four channels: i) intensive labor supply, ii) extensive labor supply, iii) the educational compositional effect, and iv) the deadweight loss. We call the educational compositional effect the change in the educational distribution relative to the baseline (see Figure 6). The deadweight loss (or production lost) is the inefficiency in production caused by the imperfect combination of different skill workers. Therefore, the deadweight loss only occurs when workers with different skills are not perfectly substitutable and the 
allocation of their skills is not optimal; i.e. the mix of labor skills that does not maximize output (Lam, 1989; Prskawetz et al., 2008). In our model, the degree of substitutability between workers is determined by the parameter $\rho$, which denotes the elasticity of substitution between different skill types.

To analyze the effect of an increase in human capital when different labor skills are imperfectly substitutable, we run six scenarios with different $\rho$ values. Specifically, for each value of $\rho$ we compare the scenario of increasing human capital to the associated status quo scenario with equal $\rho$. Following the same procedure explained in C.3, the parameters $\gamma_{i}$ 's and $B$ need to be recalibrated so that the model economy displays the same effective labor supply in the year 2000. The new set of values of $\left\{B, \gamma_{l} ; \gamma_{m}\right\}$ are $\{1.000 ; 0.2645 ; 0.5237\}$ when $\rho=0.6$ and $\{1.143 ; 0.3333 ; 0.3333\}$ when $\rho=0$ (i.e. perfect substitutability).

The central panel of Table 6 shows the economic consequences of an increase in human capital in our baseline scenario (i.e. $\rho=0.2$ ). The increasing share of high and medium skill workers relative to low skill workers (see Figure 6) lead to a reduction in their skill premiums by $24 \%$ and $8 \%$, respectively, compared to the baseline scenario in the year 2100 (columns 13 and 14). At the individual level, neither the positive income effect for low skill workers nor the negative income effect for medium and high skill workers translate into significant changes in their labor supplies at the intensive and extensive margin. Nevertheless, changes in the average work effort and retirement age can be observed in columns 5 and 6 because of the educational compositional effect. At the aggregate level, the effective labor supply, and hence output per capita, increase by $6 \%$ due to the educational compositional effect in the year 2100 (cf. Table 6, column 4). Consumption per capita increases less than effective labor supply and output per capita (cf. columns 2-4). The lost of capital income taxes, due to the decline in financial wealth to output ratio (column 12), and the additional cost of education (column 11) are balanced through higher consumption tax, which reduces consumption per capita. Importantly, the postponement of the average retirement age (column 6) and the decrease of the benefit ratio (column 10) positively affect the social contribution rate during the worse period 2060-2090.

In the case of perfect substitutability between different labor skills (i.e. $\rho=$ 0 ), the effective labor supply increases up to $14 \%$ relative to the status quo in the year 2100. This value is greater than our benchmark model with $\rho=0.2$ (cf. column 4) because there is no deadweight loss. Similar to the benchmark scenario, the change in the average work effort and retirement age by $-0.7 \%$ and $1.1 \%$ by 2100 are due to the educational compositional effect (cf. Table 6 , last panel, columns 5 and 6 ). Under this setup, education costs increase less rapidly than output and, consequently, the education to output ratio decreases around $2 \%$ in the year 2100 relative to its baseline.

On the contrary, if we consider that $\rho=0.6$, raising human capital increases the deadweight loss significantly. The new educational distribution becomes less efficient, decreasing the wage premium for medium and high skill workers up to $23 \%$ and $57 \%$, respectively. At the individual level, the average retirement age does not change by educational attainment, while work effort increases at the end of working life for low and medium skill workers. However, at the aggregate 
Table 6: Economic impact of investing in human capital, by skill substitutability

\begin{tabular}{|c|c|c|c|c|c|c|c|c|c|c|c|c|c|}
\hline \multirow[t]{2}{*}{ Year } & $\begin{array}{r}\text { Output } \\
\text { per } \\
\text { capita }\end{array}$ & $\begin{array}{r}\text { Consum. } \\
\text { per } \\
\text { capita }\end{array}$ & $\begin{array}{r}\text { Effec. } \\
\text { labor } \\
\text { supply }\end{array}$ & $\begin{array}{l}\text { Aver. } \\
\text { work } \\
\text { effort }\end{array}$ & $\begin{array}{l}\text { Aver. } \\
\text { retire. } \\
\text { age }\end{array}$ & $\begin{array}{l}\text { Social } \\
\text { secur. } \\
\text { tax }\end{array}$ & $\begin{array}{r}\text { Indirect } \\
\operatorname{tax}\end{array}$ & $\begin{array}{r}\text { Pension } \\
\text { to } \\
\text { output }\end{array}$ & $\begin{array}{r}\text { Benefit } \\
\text { ratio }\end{array}$ & $\begin{array}{r}\text { Educ. } \\
\text { to } \\
\text { output }\end{array}$ & $\begin{array}{r}\text { Wealth } \\
\text { to } \\
\text { output }\end{array}$ & \multicolumn{2}{|c|}{$\begin{array}{c}\text { Wage } \\
\text { premium }\end{array}$} \\
\hline & II & III & IV & $\mathrm{V}$ & VI & VII & VIII & IX & $\mathrm{X}$ & XI & XII & XIII & XIV \\
\hline \multicolumn{14}{|c|}{$\begin{array}{l}\text { Model economy with } \rho=0.6 ; B=1.000 ; \gamma_{l}=0.2645 ; \gamma_{m}=0.5237 \\
\text { (\% change with respect to its baseline) }\end{array}$} \\
\hline 2000 & 0.0 & 0.0 & 0.0 & 0.0 & -0.1 & -1.1 & -0.1 & -0.2 & -0.6 & 0.3 & 0.4 & 0.3 & -0.2 \\
\hline 2005 & 0.1 & 0.0 & 0.1 & -0.1 & 0.0 & -0.4 & -0.2 & -0.1 & -0.1 & 0.0 & 0.4 & 0.2 & -0.9 \\
\hline 2010 & 0.9 & 0.1 & 0.9 & -0.7 & 0.6 & 0.1 & -0.2 & -3.9 & -0.4 & -1.3 & -0.4 & -1.6 & -1.1 \\
\hline 2020 & 0.3 & -0.2 & 0.3 & 0.3 & 0.0 & -0.9 & 2.3 & 0.0 & 0.0 & 2.7 & 0.1 & -0.4 & -1.6 \\
\hline 2030 & -0.5 & -1.0 & -0.5 & 0.2 & 0.0 & 2.8 & 11.4 & 1.5 & 1.7 & 14.5 & 1.2 & -1.1 & -7.6 \\
\hline 2040 & -1.3 & -1.9 & -1.3 & 0.8 & 0.0 & 1.0 & 16.2 & 2.0 & 2.5 & 21.3 & 2.6 & -2.8 & -17.0 \\
\hline 2050 & -4.6 & -3.0 & -4.6 & 0.4 & -0.6 & 5.1 & 12.8 & 8.0 & 5.5 & 24.2 & 6.7 & -9.7 & -36.4 \\
\hline 2060 & -7.4 & -3.9 & -7.4 & -3.4 & 0.2 & 12.9 & 4.8 & 7.3 & 10.0 & 16.2 & 7.7 & -16.6 & -55.8 \\
\hline 2070 & -9.1 & -5.7 & -9.1 & -3.4 & 0.0 & 12.3 & 7.8 & 8.7 & 10.2 & 18.2 & 2.5 & -22.3 & -45.9 \\
\hline 2080 & -6.0 & -7.3 & -6.0 & -0.8 & 0.2 & 2.9 & 18.2 & 0.0 & 1.3 & 21.0 & -8.2 & -22.0 & -52.6 \\
\hline 2090 & -4.2 & -8.7 & -4.2 & -0.3 & 1.1 & -1.7 & 22.0 & -6.3 & -0.8 & 18.2 & -13.3 & -23.0 & -56.0 \\
\hline 2100 & -5.8 & -9.7 & -5.8 & 0.0 & 0.5 & -2.1 & 22.8 & -1.5 & 1.3 & 20.2 & -13.2 & -23.2 & -56.6 \\
\hline \multicolumn{14}{|c|}{$\begin{array}{l}\text { Model economy with } \rho=0.2 ; B=1.086 ; \gamma_{l}=0.3062 ; \gamma_{m}=0.3961 \\
\text { (\% change with respect to its baseline) }\end{array}$} \\
\hline 2000 & 0.0 & 0.0 & 0.0 & 0.1 & 0.0 & $\begin{array}{l}-0.2 \\
\end{array}$ & 0.2 & -0.1 & -0.1 & 0.0 & -0.1 & 0.0 & -0.1 \\
\hline 2005 & 0.0 & 0.0 & 0.0 & 0.1 & 0.0 & 0.0 & 0.2 & -0.1 & -0.1 & 0.0 & 0.0 & 0.0 & -0.2 \\
\hline 2010 & 0.4 & 0.0 & 0.4 & -0.2 & 0.3 & -0.7 & 0.1 & -2.1 & -0.1 & -0.6 & -0.2 & 0.2 & 0.0 \\
\hline 2020 & 1.3 & 0.0 & 1.3 & -0.6 & 0.6 & -0.6 & 2.6 & -2.1 & 2.5 & 0.9 & -0.9 & -0.4 & -0.8 \\
\hline 2030 & -0.2 & -0.4 & -0.2 & -0.5 & 0.0 & 0.9 & 11.8 & -0.3 & -0.3 & 14.9 & 0.6 & -0.5 & -3.2 \\
\hline 2040 & -0.5 & -0.3 & -0.5 & -0.9 & -0.2 & 0.9 & 16.8 & 1.3 & 0.5 & 22.0 & 0.6 & -1.8 & -7.5 \\
\hline 2050 & 0.4 & 0.1 & 0.4 & -0.9 & -0.2 & 0.1 & 19.3 & 0.0 & -1.1 & 23.8 & -2.1 & -4.2 & -13.6 \\
\hline 2060 & 2.6 & 0.6 & 2.6 & -0.3 & -0.2 & -1.4 & 21.7 & -2.9 & -4.5 & 22.3 & -7.3 & -6.8 & -19.8 \\
\hline 2070 & 5.4 & 1.2 & 5.4 & -0.2 & 0.5 & -3.5 & 23.7 & -6.1 & -4.6 & 21.0 & -12.3 & -8.3 & -22.5 \\
\hline 2080 & 7.7 & 2.0 & 7.7 & 0.2 & 0.9 & -7.6 & 25.0 & -7.1 & -2.9 & 20.8 & -14.2 & -8.5 & -23.4 \\
\hline 2090 & 7.1 & 3.1 & 7.1 & -0.3 & 0.8 & -3.6 & 21.8 & -2.2 & 2.6 & 19.8 & -12.7 & -8.3 & -24.1 \\
\hline 2100 & 5.8 & 3.7 & 5.8 & -0.5 & 0.5 & 0.0 & 19.9 & 2.2 & 5.7 & 20.8 & -11.5 & -8.3 & -24.2 \\
\hline \multicolumn{14}{|c|}{$\begin{array}{l}\text { Model economy with } \rho=0.0 ; B=1.143 ; \gamma_{l}=0.3333 ; \gamma_{m}=0.3333 \\
\text { (\% change with respect to its baseline) }\end{array}$} \\
\hline 2000 & 0.0 & 0.0 & 0.0 & 0.0 & 0.0 & $\begin{array}{l}-0.4 \\
\end{array}$ & -0.1 & 0.0 & 0.0 & 0.1 & 0.2 & 0.0 & 0.0 \\
\hline 2005 & 0.8 & 0.1 & 0.8 & -0.4 & 0.6 & -0.6 & 0.1 & -3.9 & -0.9 & -1.1 & -0.5 & 0.0 & 0.0 \\
\hline 2010 & -0.1 & 0.0 & -0.1 & -0.1 & 0.0 & -0.1 & -0.3 & 0.1 & 0.1 & 0.0 & 0.4 & 0.0 & 0.0 \\
\hline 2020 & 1.1 & 0.1 & 1.1 & -0.8 & 0.6 & 0.0 & 0.0 & -1.4 & 3.4 & -1.7 & -0.8 & 0.0 & 0.0 \\
\hline 2030 & 0.6 & 0.5 & 0.6 & -0.8 & 0.1 & -0.6 & 0.3 & -1.8 & -1.2 & -0.3 & -1.0 & 0.0 & 0.0 \\
\hline 2040 & 0.8 & 1.4 & 0.8 & -1.4 & 0.0 & -0.5 & 0.8 & -0.6 & -0.8 & 0.1 & -2.9 & 0.0 & 0.0 \\
\hline 2050 & 2.9 & 2.5 & 2.9 & -1.2 & -0.2 & -2.6 & 4.1 & -1.8 & -3.2 & 0.9 & -7.7 & 0.0 & 0.0 \\
\hline 2060 & 6.7 & 3.7 & 6.7 & -0.3 & -0.6 & -2.5 & 9.2 & -4.1 & -8.1 & 2.0 & -14.5 & 0.0 & 0.0 \\
\hline 2070 & 14.4 & 5.4 & 14.4 & -0.2 & 1.1 & -6.3 & 13.1 & -14.2 & -10.8 & -1.9 & -21.8 & 0.0 & 0.0 \\
\hline 2080 & 17.0 & 7.6 & 17.0 & -0.7 & 2.1 & -6.6 & 11.2 & -13.8 & -4.9 & -4.0 & -21.2 & 0.0 & 0.0 \\
\hline 2090 & 14.2 & 9.6 & 14.2 & -0.4 & 0.9 & -0.8 & 7.0 & -2.2 & 2.6 & -1.8 & -16.7 & 0.0 & 0.0 \\
\hline 2100 & 13.6 & 10.9 & 13.6 & -0.7 & 1.1 & 0.6 & 4.5 & 1.6 & 8.3 & -2.2 & -15.0 & 0.0 & 0.0 \\
\hline
\end{tabular}

Note: Differences in the average retirement age (column 6) are in absolute values. 
level, Table 6, column 5, shows a negative effect during the period 2060-2090 because of the educational compositional effect (since the relative size of low and medium skill workers decrease). As a consequence, the effective labor supply and output per capita decrease by $6 \%$ in the year 2100 relative to its baseline, partly due to the decline in the work effort and partly due to the deadweight loss (cf. Table 6, top panel, columns 2 and 4).

In sum, the comparison between the alternative $\rho$ values suggest that an educational reform would not work, unless there is a production process reform at the firm level aiming at reducing the deadweight loss.

\section{Discussion and conclusions}

In Austria, public pension expenditures are already among the highest in Europe and, at the same time, the average retirement age is among the lowest in OECD member countries. The demographic challenges that Austria will face in the next decades will put even more pressure on the sustainability of the social security system. According to the medium variant forecast of the UN, Population Division, the share of population over age 61 is expected to increase from $25 \%$ in 2001 to almost $40 \%$ in 2060 , while the labor force is expected to decline from 2020 onwards. To improve the sustainability of the social insurance, the Austrian pension system has introduced several reforms in 2000, 2003, and 2004 aiming at delaying the retirement age, reducing the average replacement rate, and making the pension system more actuarially fair.

This paper investigates the role of the recent pension reforms for the evolution of the pension debt and economic growth in Austria by comparing the status quo situation of the current pension system with alternative scenarios of the pension reforms and alternative scenarios of the change in the educational distribution.

Under the assumption of a small open economy, we have implemented a computable general equilibrium model that is built up of overlapping generations that differ by their household structure, longevity, educational attainment, and capital accumulation. Each individual optimally decides over its consumption paths and retirement age and hence indirectly determines its life cycle savings. In Table 7 we summarize our findings distinguishing between the short (2030), medium (2060) and long run (2100) impact of the various scenarios on economic variables.

Our results indicate that the pension reforms implemented in 2000, 2003, and 2004 have a pronounced effect on limiting the growing pension expenditures in the long run. Without these reforms the average retirement age would have remained at age 57 and the social security tax rate would have required to increase by $53-74 \%$ in the period $2020-2100$ to finance growing pension outlays (all comparisons are always with reference to the baseline scenario of the status quo). These higher effective taxes on hours worked would have decreased the work intensity. Both effects combined, i.e. a lower retirement age and a reduction in the work intensity in case the pension reforms would not have been 
implemented, would have decreased the effective labor supply by $10-15 \%$. This would have translated also into the same decline in output per capita. Consequently, the pension to output ratio is would have been $40-60 \%$ higher as compared to the baseline scenario.

We have also analyzed alternative policies that help to cope with the increasing cost of population aging. We have implemented the following systems: notional defined benefits (NDB) and notional defined contributions (NDC) pension systems, alternative approaches for financing the deficit of the pension system through indirect taxes (i.e. government public budget) and, the impact of increasing investments into human capital.

Among the presented scenarios, the NDC system turns out to be the most effective one in limiting the growth of pension to output ratio and it also yields the highest per capita output. These positive effects of the NDC system come through the huge increase in retirement age of 5 to 7 years compared to the baseline scenario. The increase in the retirement age starts shortly after the NDC system is introduced. This makes the NDC system appealing for bridging the future decades that will experience a strong increase in pension expenditures caused by the retirement of the baby boom generations. The NDC reduces the pension to output ratio the most among all presented scenarios also in the long run. However, these positive effects come at the cost of a strong increase in indirect tax rate until the system is mature.

In the unbalanced pension system scenario we allow for an unbalanced pension system by keeping (similar to the NDC) the social contribution rate fixed at the level from year 2005 (22.8\% of gross wage) and allow pension expenditures to grow as induced by population aging. The increasing gap between pension outlays and revenues is covered through the indirect taxes, i.e. through the general government budget. Since this scenario results in lower taxation of labor income (whereas the taxation of consumption is the highest among all scenarios) savings increase the most in this scenario, resulting in about a one third higher financial wealth to output ratio in 2100 . The NDB has a small, but positive impact on the economic outcome compared to the status quo scenario due to the lower effective tax on hours worked, which stimulates work effort. The impact of higher human capital investment on economic growth depends on the degree of imperfect substitutability between workers with different educational levels. Under the baseline scenario, we show that human capital increases output per capita and positively affect the social contribution rate during the worse period 2060-2090. However, if the elasticity of substitution between different labor supplies increases, it may lead to a reduction in economic growth when different skill workers are not optimally combined.

In both the NDC and the NDB we assume that social contributions are capitalized according to the (net) interest rate from private markets. Therefore, there is no effective social contribution tax, which otherwise imposes an additional tax on hours worked (or subsidy, if social contributions are capitalized at the higher rate than the (net) interest rate from private markets). Under these assumptions the NDC and the NDB have the advantage of not causing negative distortion on the intensive labor supply. The effective tax on hours worked 
is therefore only a function of the labor income tax rate and the consumption tax rate. However, in the NDC the consumption tax has to increase strongly to finance the difference between pension outlays and revenues. Assuming an increase also in the capital income tax and the labor income tax would probably be more realistic. This would lead to a lower wealth-to-output ratio and a lower effective labor supply.

Table 7: Summary of the economic impact of alternative policies relative to the baseline scenario (in \%)

\begin{tabular}{|c|c|c|c|c|c|c|c|c|c|c|c|}
\hline \multirow[t]{2}{*}{ Year } & $\begin{array}{r}\text { Output } \\
\text { per } \\
\text { capita }\end{array}$ & $\begin{array}{r}\text { Consum. } \\
\text { per } \\
\text { capita }\end{array}$ & $\begin{array}{l}\text { Effec. } \\
\text { labor } \\
\text { supply }\end{array}$ & $\begin{array}{l}\text { Aver. } \\
\text { work } \\
\text { effort }\end{array}$ & $\begin{array}{r}\text { Aver. } \\
\text { retire. } \\
\text { age }\end{array}$ & $\begin{array}{r}\text { Social } \\
\text { secur. } \\
\text { tax }\end{array}$ & $\begin{array}{r}\text { Indirect } \\
\text { tax }\end{array}$ & $\begin{array}{r}\text { Pension } \\
\text { to } \\
\text { output }\end{array}$ & $\begin{array}{r}\text { Benefit } \\
\text { ratio }\end{array}$ & $\begin{array}{r}\text { Educ. } \\
\text { to } \\
\text { output }\end{array}$ & $\begin{array}{r}\text { Wealth } \\
\text { to } \\
\text { output }\end{array}$ \\
\hline & II & III & IV & $\mathrm{V}$ & VI & VII & VIII & IX & $\mathrm{X}$ & $\mathrm{XI}$ & XII \\
\hline \multicolumn{12}{|l|}{2030} \\
\hline No Reform & -15.6 & -5.1 & -15.6 & 4.1 & -5.0 & 76.3 & -6.0 & 60.0 & 22.9 & 4.8 & 1.2 \\
\hline NDB & 3.5 & 0.8 & 3.5 & 2.1 & 0.0 & -0.8 & 3.5 & -1.8 & -2.1 & 0.1 & -2.7 \\
\hline $\mathrm{NDC}$ & 15.7 & 7.1 & 15.7 & -8.2 & 6.8 & -34.8 & -35.4 & -39.9 & 0.4 & -12.7 & -21.3 \\
\hline Unbalanced & 3.3 & -3.4 & 3.3 & 2.1 & 0.2 & -34.8 & 142.1 & -4.4 & -3.2 & 4.7 & -6.7 \\
\hline Human Capital & -0.2 & -0.4 & -0.2 & -0.5 & 0.0 & 0.9 & 11.8 & -0.3 & -0.3 & 14.9 & 0.6 \\
\hline \multicolumn{12}{|l|}{2060} \\
\hline No Reform & -11.1 & -12.4 & -11.1 & 9.7 & -5.4 & 53.7 & 20.2 & 41.8 & 12.3 & 6.2 & -28.1 \\
\hline NDB & 5.2 & 2.6 & 5.2 & 3.9 & 0.0 & -0.7 & 1.4 & -2.3 & -2.7 & 0.1 & 0.5 \\
\hline NDC & 11.5 & 0.8 & 11.5 & -8.2 & 5.9 & -45.7 & 151.4 & -9.3 & 31.8 & -7.0 & 0.9 \\
\hline Unbalanced & 1.2 & -4.2 & 1.2 & 1.0 & 0.2 & -45.7 & 213.4 & 5.2 & 7.3 & 8.1 & 20.2 \\
\hline Human Capital & 2.6 & 0.6 & 2.6 & -0.3 & -0.2 & -1.4 & 21.7 & -2.9 & -4.5 & 22.3 & -7.3 \\
\hline \multicolumn{12}{|l|}{2100} \\
\hline No Reform & -13.2 & -17.3 & -13.2 & 8.1 & -6.2 & 67.3 & 24.9 & 54.6 & 18.8 & 5.5 & -44.9 \\
\hline NDB & 3.3 & 3.7 & 3.3 & 2.9 & -0.4 & 0.2 & -1.5 & 1.7 & -0.5 & 1.0 & 3.1 \\
\hline NDC & 6.3 & 6.2 & 6.3 & -8.3 & 5.0 & -37.5 & 82.4 & -5.2 & 27.6 & -5.0 & 14.4 \\
\hline Unbalanced & -1.6 & 1.6 & -1.6 & -0.8 & -0.2 & -37.5 & 122.1 & 6.9 & 6.6 & 6.9 & 32.5 \\
\hline Human Capital & 5.8 & 3.7 & 5.8 & -0.5 & 0.5 & 0.0 & 19.9 & 2.2 & 5.7 & 20.8 & -11.5 \\
\hline
\end{tabular}

Notes: column 6, 'Average retirement age', contains absolute differences with respect to the baseline. NDB and NDC stand for notional defined benefit system and notional defined contribution system respectively. 'Unbalanced' refers to an unbalanced pension system with a social contribution rate set to $22.8 \%$ from year 2005 onwards. 'Human capital' scenario corresponds to a policy that progressively increases the educational attainment for cohorts born between 1995 and 2010 .

\section{References}

Acemoglu, D., Autor, D., June 2012. What does human capital do? A review of Goldin and Katz's the race between education and technology. Journal of Economic Literature 50 (2), 426-463.

Attanasio, O. P., Weber, G., September 2010. Consumption and saving: models of intertemporal allocation and their implications for public policy. Journal of Economic Literature 48, 693-751. 
Auerbach, A. J., Lee, R. D., 2006. Notional defined contribution pension systems in a stochastic context: Design and stability. In Social Security Policy in a Changing Environment. University of Chicago Press, pp. 43-68.

Boucekkine, R., de la Croix, D., Licandro, O., 2002. Vintage human capital, demographic trends, and endogenous growth. Journal of Economic Theory $104,340-375$.

Braun, A. R., Ikeda, D., Joines, D. H., January 2009. The saving rate in Japan: Why it has fallen and why it will remain low. International Economic Review 50 (1), 291-321.

Browning, M., Ejrnaes, M., February 2009. Consumption and children. The Review of Economics and Statistics 91 (1), 93-111.

Browning, M., Lusardi, A., December 1996. Household saving: Micro theories and micro facts. Journal of Economic Literature 34 (4), 1797-1855.

Curtis, C. C., Lugauer, S., Mark, N. C., February 2011. Demographic patterns and household saving in China. NBER Working Paper Series (16828), 1-21.

d'Albis, H., Augeraud-Véron, E., 2008. Endogenous retirement and monetary cycles. Mathematical Population Studies 15, 214-229.

d'Albis, H., Lau, P., Sanchez-Romero, M., January 2012. Mortality transition and differential incentives for early retirement. Journal of Economic Theory 147 (1), 261-283.

Fisher, W. H., Keuschnigg, C., 2010. Pension reform and labor market incentives. Journal of Population Economics 23, 769-803.

Gertler, M., 1999. Government debt and social security in a life-cycle economy. Carnegie-Rochester Conference Series on Public Policy 50, 61-110.

Gruber, J., Wise, D. A. (Eds.), 1999. Social Security and Retirement Around the World. National Bureau of Economic Research.

Gruber, J., Wise, D. A. (Eds.), 2004. Social Security and Retirement Around the World: Micro-Estimation. University of Chicago Press.

Gruber, J., Wise, D. A. (Eds.), 2007. Social Security Programs and Retirement Around the World: Fiscal Implications. National Bureau of Economic Research.

Heckman, J., MaCurdy, T., 1980. A life cycle model of female labor supply. Review of Economic Studies 47 (1), 47-74.

Heckman, J., MaCurdy, T., 1982. Corrigendum on a life cycle model of female labour supply. Review of Economic Studies 49 (4), 659-660. 
Heijdra, B. J., Romp, W. E., 2009. Retirement, pensions, and ageing. Journal of Public Economics 93, 586-604.

Hofer, H., Koman, R., December 2006. Social security and retirement in Austria. Empirica 33 (5), 285-313.

Holzmann, R., Palmer, E. (Eds.), 2006. Pension Reforms: Issues and Prospects for Non-Financial Defined Contribution (NDC) Schemes. The World Bank, Washington, D.C.

Human Fertility Database, 2011. Max Planck Institute for Demography Research (Germany), and Vienna Institute of Demography (Austria). Available at www.humanfertility.org (data download on June 2011).

Human Life Tables, 2011. Max Planck Institute for Demography Research (Germany)Available at http://www.lifetable.de. (data download on June 2011).

Human Mortality Database, 2010. University of California, Berkeley (USA), and Max Planck Institute for Demography Research (Germany). Available at www.mortality.org or www.humanmortality.de (data download on February 2010).

Imrohoroglu, S., Kitao, S., July 2012. Social security reforms: Benefit claiming, labor force participation, and long-run sustainability. American Economic Journal: Macroeconomics 4 (3), 96-127.

IPUMS-International, 2011. Minnesota Population Center. Integrated Public Use Microdata Series, International: Version 6.1 [Machine-readable database].

Jaag, C., Keuschnigg, C., Keuschnigg, M., 2010. Pension reform, retirement, and life-cycle unemployment. International Tax Public Finance 17, 556-585.

Kalwij, A., May 2010. The impact of family policy expenditure on fertility in western Europe. Demography 47 (2), 503-519.

Keane, M. P., December 2011. Labor supply and taxes: A survey. Journal of Economic Literature 49 (4), 961-1075.

Keane, M. P., Rogerson, R., June 2012. Micro and macro labor supply elasticities: A reassessment of conventional wisdom. Journal of Economic Literature $50(2), 464-476$.

Keuschnigg, C., Keuschnigg, M., 2004. Aging, labor markets and pension reform in Austria. Finanzarchiv 60 (3), 359-392.

Knell, M., Köhler-Töglhofer, W., Prammer, D., August 2006. The Austrian pension system - how recent reforms have changed fiscal sustainability and pension benefits. Monetary Policy and the Economy (2), 69-93. 
Lam, D., 1989. Population growth, age structure, and age-specific productivity: Does a uniform age distribution minimize lifetime wages? Journal of Population Economics 2, 189-210.

Lee, R. D., 1985. Inverse projection and back projection: A critical appraisal, and comparative results for England, 1539 to 1871. Population Studies 39, $233-248$.

Lee, R. D., Mason, A., Miller, T., 2000. Life cycle saving and the demographic transition: The case of Taiwan. Population and Development Review 26, 194219 .

Leslie, P. H., 1945. On the use of matrices in certain population dynamics. Biometrika 33, 183-212.

Ludwig, A., Reiter, M., November 2010. Sharing demographic risk - who is afraid of the baby bust? American Economic Journal: Economic Policy 2 (4), $83-118$.

Mara, I., Narazani, E., 2001. Labour-incentive reforms at preretirement age in Austria. Empirica 38, 481-510.

OECD, 2005. Ageing and employment policies: Austria. Tech. rep., Organisation for Economic Co-operation and Development.

Oeppen, J., 1993. Back projection and inverse projection: Members of a wider class of constrained projection models. Population Studies 47, 245-267.

Preston, S. H., Heuveline, P., Guillot, M., 2002. Demography: Measuring and Modeling Population Processes. Blackwell Publishers Inc., Massachusetts.

Prskawetz, A., Fent, T., Guest, R., 2008. Workforce aging and labor productivity: The role of supply and demand for labor in the G7 countries. Population and Development Review 34, 298-323.

Rojas, J. A., 2005. Life-cycle earnings, cohort size effects and social security: A quantitative exploration. Journal of Public Economics 89, 465-485.

Sambt, J., Prskawetz, A., 2011. National Transfer Accounts for Austria: Low levels of education and the generosity of the social security system. In Population Aging and the Generational Economy: A Global Perspective. Edward Elgar, Cheltenham, Northampton, Ch. , pp. 256-268.

Samir, K., Barakat, B., Goujon, A., Skirbekk, V., Sanderson, W. C., Lutz, W., 2010. Projection of populations by level of educational attainment, age, and sex for 120 countries for 2005-2050. Demographic Research 22 (15), 383-472.

Staubli, S., Zweimüller, J., 2011. Does raising the retirement age increase employment of older workers? University of Zurich, Working Paper Series, ISSN 1664-705X. 
UN Population Division, January 2011. Department of Economics and Social Affairs, Population Division, World Population Prospects: The 2008 Revision Data available at http://esa.un.org/unpp.

Yaari, M., April 1965. Uncertain lifetime, life insurance, and the theory of the consumer. The Review of the Economic Studies 5 (3), 304-317.

\section{A Household problem}

For notational simplicity and without lost of generality we get rid of subscripts that denote labor skill, $i$, and time $t$. Differentiating (7) with respect to consumption and leisure, subject to (4)-(6) and the boundary condition, give the first-order conditions $(8 \mathrm{a})-(8 \mathrm{~b})$, respectively.

The envelope conditions are

$$
V_{a}\left(a_{x}, P_{x} ; z\right)=\beta(1+\bar{r}) \frac{\pi_{x+1}}{\pi_{x}} V_{a}\left(a_{x+1}, P_{x+1} ; z\right),
$$

$$
\begin{aligned}
& V_{P}\left(a_{x}, P_{x} ; z\right) \\
= & \left\{\begin{array}{l}
\beta(1+\tilde{r}) \frac{\pi_{x+1}}{\pi_{x}} V_{P}\left(a_{x+1}, P_{x+1} ; z\right) \\
\beta \pi_{x+1} V_{a}\left(a_{x+1}, P_{x+1} ; z\right)\left(1-\tau_{l}\right) v_{x}+\beta \pi_{x+1}\left(\frac{1+\tilde{r}}{\pi_{x}}-v_{x}\right) V_{P}\left(a_{x+1}, P_{x+1} ; z\right)
\end{array}\right.
\end{aligned}
$$

if $x<\max \left(z, z_{e}\right)$, if $x \geq \max \left(z, z_{e}\right)$,

Combining the envelope condition (30a) with the first-order conditions (8a)-(8b) give

$$
\begin{aligned}
\frac{u_{c}\left(c_{x}, 1-l_{x} ; \eta_{x}\right)}{u_{c}\left(c_{x+1}, 1-l_{x+1} ; \eta_{x}\right)} & =\beta(1+\bar{r}) \frac{1+\tau_{c, x}}{1+\tau_{c, x+1}} \\
\frac{u_{1-l}\left(c_{x}, 1-l_{x} ; \eta_{x}\right)}{u_{c}\left(c_{x}, 1-l_{x} ; \eta_{x}\right)} & =\omega_{x} \epsilon_{x}\left(1-t_{x}^{E}\right) \text { if } l_{x}>0 .
\end{aligned}
$$

Eq (31a) is the well-known Euler condition. Now, using the period utility function (5) in (31b) we define the leisure to adult consumption ratio (lcr) at age $x$ as

$$
l c r_{x} \equiv \frac{1-l_{x}}{c_{x} / \eta_{x}}=\frac{1-\phi}{\phi}\left(\omega_{x} \epsilon_{x}\left(1-t_{x}^{E}\right)\right)^{-1} .
$$

From Eq (32) we obtain the work effort at age $x$ as

$$
l_{x}=\max \left(0,1-\frac{1-\phi}{\phi} \frac{c_{x}}{\eta_{x}}\left(\omega_{x} \epsilon_{x}\left(1-t_{x}^{E}\right)\right)^{-1}\right) .
$$




\section{B Proof of Proposition 1}

Proof. Recall the marginal rate of substitution between public pension wealth and assets holding, which is denoted by $\xi_{x}(z)$, is defined as $V_{P}(a, P ; z) / V_{a}(a, P ; z)$. Then, dividing (30b) by (30a),

$$
\begin{aligned}
& \xi_{x}(z) \\
& = \begin{cases}\frac{1+\tilde{r}}{1+\bar{r}} \xi_{x+1}(z) & \text { if } x_{0} \leq x<\max \left(z, z_{e}\right), \\
\frac{\pi_{x}}{1+\bar{r}}\left(1-\tau_{l}\right) v_{x}+\frac{\pi_{x}}{1+\bar{r}}\left(\frac{1+\tilde{r}}{\pi_{x}}-v_{x}\right) \xi_{x+1}(z) & \text { if } \max \left(z, z_{e}\right) \leq x<\Omega, \\
0 & \text { if } x=\Omega .\end{cases}
\end{aligned}
$$

Notice that the value of $\xi_{x}(z)$, for any $x \geq \max \left(z, z_{e}\right)$, can be calculated applying (34) recursively from age $\Omega-1$ until $x$. Since by assumption $v_{x} P_{x}=b(z)$ for all $x \geq \max \left(z, z_{e}\right)$, it holds

$$
P_{x} \xi_{x}(z)=\left(1-\tau_{l}\right) b(z) \sum_{s=x}^{\Omega-1}\left(\prod_{z=x}^{s} \frac{\pi_{z}}{1+\bar{r}}\right),
$$

which would be the present value of an annuity of $\left(1-\tau_{l}\right) b(z)$ paid from age $x$ until death by a private pension system. Now, applying (4) recursively until the same age $x$ gives

$$
P_{x}=b(z) \sum_{s=x}^{\Omega-1}\left(\prod_{z=x}^{s} \frac{\pi_{z}}{1+\tilde{r}}\right) .
$$

Dividing (35) by (36) and rearranging terms,

$$
\frac{\xi_{x}(z)}{1-\tau_{l}}=\frac{\sum_{s=x}^{\Omega-1}\left(\prod_{z=x}^{s} \frac{\pi_{z}}{1+\tilde{r}}\right)}{\sum_{s=x}^{\Omega-1}\left(\prod_{z=x}^{s} \frac{\pi_{z}}{1+\tilde{r}}\right)} .
$$

From (37) Proposition 1 holds.

\section{Supplementary material: Computational ap- pendix}

\section{C.1 household problem}

To solve numerically this problem we apply the usual backward-shooting algorithm on $x$ from age $\Omega-1$ until $x_{0}$ by taking both the retirement age $z$ and an initial set of final consumptions $\mathbf{c}_{\Omega-1}=\left\{\zeta_{1}, \ldots, \zeta_{m}\right\}$ as given and using the boundary conditions, which imply that $V_{a}\left(a_{\Omega}, P_{\Omega} ; z\right)=V_{P}\left(a_{\Omega}, P_{\Omega} ; z\right)=0$. Before proceeding to solve the household problem, we first calculate the internal rate of return of the public pension system $\tilde{r}_{i}$ as well as the pension benefits $b_{i}(z)$ associated to each final consumption level $\zeta_{i}>0$, for $i \in(1, \ldots, m)$. Notice 
that for an initial value $\zeta_{i}$ we can calculate the consumption and leisure paths, denoted by $\left\{\zeta_{i, x}, l_{i, x}\right\}_{x>0}$, using (9), (31a), (33)-(34). Each step is further explained below. Once that we have the labor income profile over the working-life we calculate the pension benefits $b_{i}(z)$ and define the internal rate of return of the pension system as the value of $\tilde{r}_{i}$ that satisfies:

$$
\sum_{x=0}^{z}\left(\prod_{s=0}^{x} \frac{\pi_{s}}{1+\tilde{r}_{i}}\right) \tau_{s, x} \omega_{x} \epsilon_{x} l_{i, x}=\sum_{x=\max \left(z, z_{e}\right)}^{\Omega-1}\left(\prod_{s=0}^{x} \frac{\pi_{s}}{1+\tilde{r}_{i}}\right) b_{i}(z)
$$

It is worth noticing that for a given set of $\left\{\omega_{x}, \tau_{l}, \tau_{s, x}, \tau_{c, x}, \pi_{x}, \bar{r}\right\}$ values over the life-cycle and a retirement age $z$, the internal rate of return $\tilde{r}_{i}$ is a one-to-one function with respect to the final consumption $\zeta_{i}$. Let denote the sequence of values of $\tilde{r}_{i}$ and $b_{i}(z)$ associated to each $\zeta_{i}$ by $\tilde{\mathbf{r}}$ and $\mathbf{b}(z)$, respectively.

Next, we follow the standard procedure that is summarized in the following steps:

1. We take the sequence of values $\mathbf{c}_{\Omega-1}, \mathbf{b}(z)$, and $\tilde{\mathbf{r}}$. Using the boundary conditions, we initialize the program assuming that

$$
\begin{aligned}
V_{a}\left(\mathbf{a}_{\Omega-1}, \mathbf{P}_{\Omega-1} ; z\right) & =\frac{1+\bar{r}}{\pi_{\Omega-1}} \frac{u_{c}\left(\mathbf{c}_{\Omega-1}, 1\right)}{1+\tau_{c, \Omega-1}}, \\
V_{P}\left(\mathbf{a}_{\Omega-1}, \mathbf{P}_{\Omega-1} ; z\right) & =\frac{1-\tau_{l}}{1+\tau_{c, \Omega-1}} u_{c}\left(\mathbf{c}_{\Omega-1}, 1\right) .
\end{aligned}
$$

2. Given $V_{a}(\cdot)$ we use the first-order condition $(8 \mathrm{a})$ to calculate $u_{c}(\cdot)$ one period before.

3. We calculate the consumption

$$
\mathbf{c}_{x}= \begin{cases}\eta_{x}\left(\frac{u_{c}(\cdot)}{\phi l c r^{(1-\phi)(1-\sigma)}}\right)^{\frac{-1}{1-\left(1+\phi\left(\eta_{x}-1\right)\right)(1-\sigma)}} & \text { if } x<z \\ \eta_{x}\left(\frac{u_{c}(\cdot)}{\phi}\right)^{\frac{-1}{1-\phi \eta_{x}(1-\sigma)}} & \text { if } x \geq z\end{cases}
$$

4. If the individual is retired, then $l=0$. Otherwise, we calculate the optimal number of hours worked using the fact that

$$
\mathbf{l}_{x}=1-\frac{\mathbf{c}_{x}}{\eta_{x}} \cdot l c r_{x}, \text { or } l=0 \text { if } l<0,
$$

where $l c r_{x}$ is the leisure-to-adult consumption ratio, see Eq (32).

5. If $l_{i, x}=0$ for $x<z$, we recalculate the consumption

$$
c_{i, x}=\eta_{x}\left(\frac{u_{c}(\cdot)}{\phi}\right)^{\frac{-1}{1-\phi \eta_{x}(1-\sigma)}} .
$$

6. We use (6) and (4) to obtain the sequence of values of assets $\mathbf{a}_{x}$ and public pension wealth $\mathbf{P}_{x}$ one period before for each consumption level. 
7. We apply the envelope conditions (30a)-(30b) to obtain $V_{a}(\cdot)$ and $V_{P}(\cdot)$ one period before.

8. Iterate recursively until $x=x_{0}$

9. We interpolate within the set of pair of values $\left\{\mathbf{c}_{\Omega-1}, \mathbf{a}_{x_{0}}\right\}$ to find the consumption level $\zeta^{*}$ that satisfies the initial boundary condition on asset holdings; i.e. $a_{x_{0}}=0$. Notice that $\mathbf{P}_{x_{0}}$ is by construction always a sequence of zeros.

10. Given $\zeta^{*}$, calculate the internal rate of return $\tilde{r}^{*}$, the pension benefit $b^{*}(z)$ and repeat steps 1-8.

11. Calculate the expected utility at age $x_{0}$

$$
V\left(a_{x_{0}}, P_{x_{0}} ; z\right)=\sum_{x=x_{0}}^{\Omega-1}\left(\prod_{s=x_{0}}^{x} \beta \pi_{s}\right) \frac{u\left(c_{x}, 1-l_{x} ; \eta_{x}\right)}{\beta \pi_{x_{0}}} .
$$

12. Repeat all steps for each retirement age $z \in \mathcal{Z}$.

13. Calculate the optimal retirement age $z^{*}$

$$
z^{*}=\arg \max _{z \in \mathcal{Z}} V\left(a_{x_{0}}, P_{x_{0}} ; z\right) .
$$

14. Collect the set of values $\left\{a_{x}^{*}, b^{*}\left(z^{*}\right), c_{x}^{*}, l_{x}^{*}, \tilde{r}^{*}\right\}$ from age $x_{0}$ to $\Omega-1$ for the optimal retirement age $z^{*}$.

\section{C.2 Aggregate economy}

Let assume a small-open economy with a fixed interest rate $r$. The simulation strategy is to calculate the contribution rate for a given initial vector $\left\{\tau_{s, t}^{j}\right\}_{t \in \mathcal{T}}$, with $j$ denoting the $j$-th iteration, such that pension claims equal contributions paid at all times. The information set prior to the simulation is a vector of timeinvariant parameters, demographic characteristics, and degree of technological progress for $t \in \mathcal{T}$. In order to guarantee initial and final stable results, the phase-in (out) period begin (finishes) with a stable population. The algorithm is divided into the following steps:

1. Choose a dumping factor of $\xi=0.05$ and a tolerance $\epsilon$ equal to 0.01 .

2. Make an initial guess $\left\{\tau_{s, t}^{0}\right\}_{t \in \mathcal{T}}$.

3. Compute the household problem and aggregate the household policies across all household heads to determine assets holding, pension benefits 
claimed, consumption path, and labor supply

$$
\begin{aligned}
A_{t} & =\sum_{i} \sum_{x} N_{t, x} a_{t, x}^{i} \Upsilon_{t-x}(i), \\
P B_{t} & =\sum_{i} \sum_{x} N_{t+1, x+1} b_{t, x}^{i} \Upsilon_{t-x}(i), \\
C_{t} & =\sum_{i} \sum_{x} N_{t+1, x+1} c_{t, x}^{i} \Upsilon_{t-x}(i), \\
H_{t}^{i} & =\sum_{x} \epsilon_{x}(i) l_{t, x} N_{t+1, x+1} \Upsilon_{t-x}(i), \\
H_{t} & =B\left(\sum_{i \in \mathcal{H}} \gamma_{i}\left(H_{t}^{i}\right)^{1-\rho}\right)^{\frac{1}{1-\rho}} .
\end{aligned}
$$

4. Determine the marginal product of labor for each educational attainment using Eq (18).

5. Calculate the contribution rate necessary to have a balanced pension system

$$
\tau_{s, t}^{n}=\frac{P B_{t}}{\sum_{i} \omega_{t}^{i} H_{t}^{i}} \text { for all } t \in \mathcal{T} .
$$

6. If $\left\|\tau_{s}^{n}-\tau_{s}^{j}\right\|<\epsilon$ then stop.

7. Otherwise, compute a new vector of contribution rates

$$
\tau_{s, t}^{j+1}=(1-\xi) \tau_{s, t}^{j}+\xi \tau_{s, t}^{n} \text { for all } t \in \mathcal{T} .
$$

8. Calculate a new set of total public goods and services $G_{t}$ according to (25)-(27).

9. Calculate the vector of consumption tax rates $\tau_{c, t}$ such that satisfies (20).

10. Then go to step 3 .

\section{C.3 Parameters of the effective aggregate labor input}

To properly estimate the weights on education $\left(\gamma_{i}^{\prime} s\right)$ it is necessary labor income profiles time series data. Unfortunately, the available database used for calculating labor income profiles is EU-SILC in year 2006. To overcome this problem, we assume for convenience that $y_{t_{0}, x}^{m} / y_{t_{0}, x}^{l}=\epsilon_{x}(m) / \epsilon_{x}(l)$ and $y_{t_{0}, x}^{h} / y_{t_{0}, x}^{l}=\epsilon_{x}(h) / \epsilon_{x}(l)$ in the reference year $t_{0}$. Thus, from Eqs (19a)-(19b) we have

$$
\begin{aligned}
& \frac{y_{t_{0}, x}^{m}}{y_{t_{0}, x}^{l}}=\frac{\omega_{t_{0}}^{m} \epsilon_{x}(m)}{\omega_{t_{0}}^{l} \epsilon_{x}(l)}=\left(\gamma_{m} / \gamma_{l}\right)\left(H_{t_{0}}^{m} / H_{t_{0}}^{l}\right)^{-\rho} \frac{\epsilon_{x}(m)}{\epsilon_{x}(l)} \\
& \frac{y_{t_{0}, x}^{h}}{y_{t_{0}, x}^{l}}=\frac{\omega_{t_{0}}^{m} \epsilon_{x}(h)}{\omega_{t_{0}}^{l} \epsilon_{x}(l)}=\left(\gamma_{h} / \gamma_{l}\right)\left(H_{t_{0}}^{h} / H_{t_{0}}^{l}\right)^{-\rho} \frac{\epsilon_{x}(h)}{\epsilon_{x}(l)} .
\end{aligned}
$$


Therefore,

$$
\begin{gathered}
\left(\gamma_{m} / \gamma_{l}\right)\left(H_{t_{0}}^{m} / H_{t_{0}}^{l}\right)^{-\rho}=1, \\
\left(\gamma_{h} / \gamma_{l}\right)\left(H_{t_{0}}^{h} / H_{t_{0}}^{l}\right)^{-\rho}=1 .
\end{gathered}
$$

Substituting (51)-(52) into the fact that $\sum_{i \in \mathcal{H}} \gamma_{i}=1$, gives

$$
\begin{aligned}
\gamma_{m} & =\frac{\left(H_{t_{0}}^{l} / H_{t_{0}}^{m}\right)^{-\rho}}{1+\left(H_{t_{0}}^{l} / H_{t_{0}}^{h}\right)^{-\rho}+\left(H_{t_{0}}^{l} / H_{t_{0}}^{m}\right)^{-\rho}}, \\
\gamma_{l} & =\frac{1}{1+\left(H_{t_{0}}^{l} / H_{t_{0}}^{h}\right)^{-\rho}+\left(H_{t_{0}}^{l} / H_{t_{0}}^{m}\right)^{-\rho}} .
\end{aligned}
$$

Consequently, given $\rho$ and $H_{t_{0}}^{i}$ for $i \in \mathcal{H}$, we can uniquely estimate $\left\{\gamma_{l} ; \gamma_{m}\right\}$ using the above equations .

\section{C.4 Demographics}

Let $N_{t}$ denote the total population size in year $t$ and $N_{t, x}$ be the size of the population at age $x$ in year $t$. We assume a closed population whose law of motion (or "balancing equation") is given by

$$
N_{t+1}=N_{t}+B_{t}-D_{t} .
$$

Population at time $t+1$ is given by the population in year $t$ plus the total number of births in year $t$, denoted $B_{t}$, less the total number of deaths during the year $D_{t}$. The dynamics of the population can be written in matrix notation using a Leslie matrix (Leslie, 1945; Preston et al., 2002)

$$
\mathbf{N}(t+1)=\mathbf{L}(t) \mathbf{N}(t)
$$

with

$$
\begin{aligned}
& \Gamma_{1, x}(t)=\frac{L_{t, 0}}{2 S_{t, 0}}\left(f_{t, x}+f_{t, x+1} \frac{L_{t, x+1}}{L_{t, x}}\right) f_{f a b}, \\
& \Gamma_{x+1, x}(t)=\frac{L_{t, x+1}}{L_{t, x}}, \text { for } x \in\{1, \ldots, \Omega-1\} \text { at time } t,
\end{aligned}
$$

where $L_{t, x}=\frac{S_{t, x}+S_{t, x+1}}{2}$ is the person years lived by the cohort between ages $x$ and $x+1$ in period $t, f_{t, x}$ is the age-specific fertility rate at age $x$ in year $t$, $f_{f a b}$ is the fraction of females at birth (I assume $f_{f a b}=0.4886$, which is the standard value in the demographic literature).

To reconstruct the Austrian population, we combine two demographic methods widely used in population reconstruction: Inverse Projection (IP) and Generalized Inverse Projection (GIP) (Lee, 1985; Oeppen, 1993). We use a simplified 
version of a GIP model that matches the specific characteristics of this economic model. The objective function used to solve the problem is:

$$
\begin{gathered}
\min _{\left\{\left\{\alpha_{t}^{i}, \gamma_{t}^{i}\right\}_{i=0}^{2}\right\}_{t=t_{0}}^{T}} \sum_{t \in \mathbb{D}}\left(\frac{D_{t}-\hat{D}_{t}}{D_{t}}\right)^{2}+\sum_{t \in \mathbb{B}}\left(\frac{B_{t}-\hat{B}_{t}}{B_{t}}\right)^{2}+\sum_{t \in \mathbb{N}}\left(\frac{N_{t}-\hat{N}_{t}}{N_{t}}\right)^{2}+\sum_{t \in \mathbb{E}}\left(\frac{e_{t}-\hat{e}_{t}}{e_{t}}\right)^{2} \\
+\sum_{t \in \mathbb{T}}\left(\frac{\operatorname{tfr}_{t}-\hat{t f r}_{t}}{\operatorname{tfr}_{t}}\right)^{2}+\sum_{t \in \mathbb{C}} \sum_{a=0}^{\Omega-1}\left(\frac{N_{a, t}-\hat{N}_{a, t}}{N_{t}}\right)^{2}+\sum_{t=t_{0}}^{T} \sum_{i=0}^{2}\left(\alpha_{t+1}^{i}-\alpha_{t}^{i}\right)^{2}+\left(\gamma_{t+1}^{i}-\gamma_{t}^{i}\right)^{2},
\end{gathered}
$$

subject to equations (56)-(57) and to

$$
f_{t, x}=\sum_{i} \alpha_{t}^{i} f_{x}^{(i)}, \quad\left(1-\pi_{t, x}\right)=\sum_{i} \gamma_{t}^{i}\left(1-\pi_{x}^{(i)}\right), \quad \sum_{i} \alpha_{t}^{i}=1, \quad \sum_{i} \gamma_{t}^{i}=1
$$

where $\left\{\left\{\alpha_{t}^{i}, \gamma_{t}^{i}\right\}_{i=0}^{2}\right\}_{t=t_{0}}^{T}$ are the set of parameters for mortality and fertility, respectively; $f_{x}^{(i)}$ and $\pi_{x}^{(i)}$ are actual age-specific fertility rates and conditional survival probability by age for specific years; tfr stands for total fertility rate; $e$ denotes life expectancy at birth; and $\mathbb{I} \equiv\{\mathbb{D}, \mathbb{B}, \mathbb{N}, \mathbb{E}, \mathbb{T}, \mathbb{C}\}$ are the sets of deaths, births, total population, life expectancy, total fertility rates, and censuses used in the calculation. Crude migration rates are obtained using inverse population projection and are exogenous to the GIP model. The information set (I) started from reconstructing the main demographic variables for Austria from 1871 up to now using demographic data from the Human Mortality Database, the Human Fertility Database, the Human Life Tables and Statistics Austria. From year 2010 onwards, our population forecast is based on the assumptions of UN Population Division for Austria (case: medium variant). Figure 7 shows the evolution of the total fertility rate (TFR) and dependency ratios (youth and aged) implemented in our model from year 1900 to 2100 . 


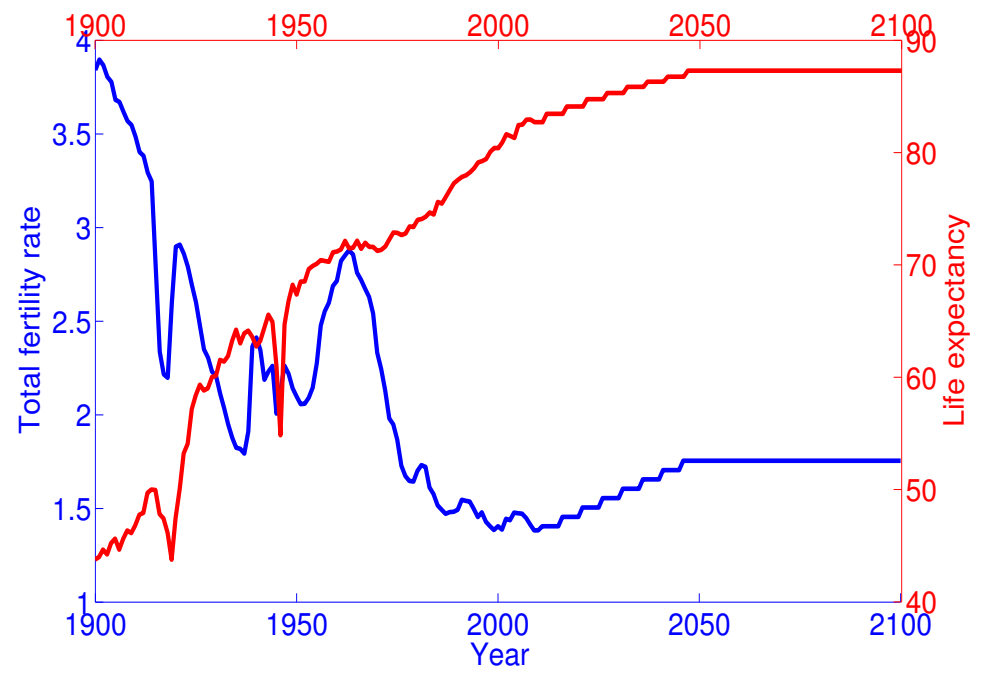

(a) Total fertility rate and Life expectancy

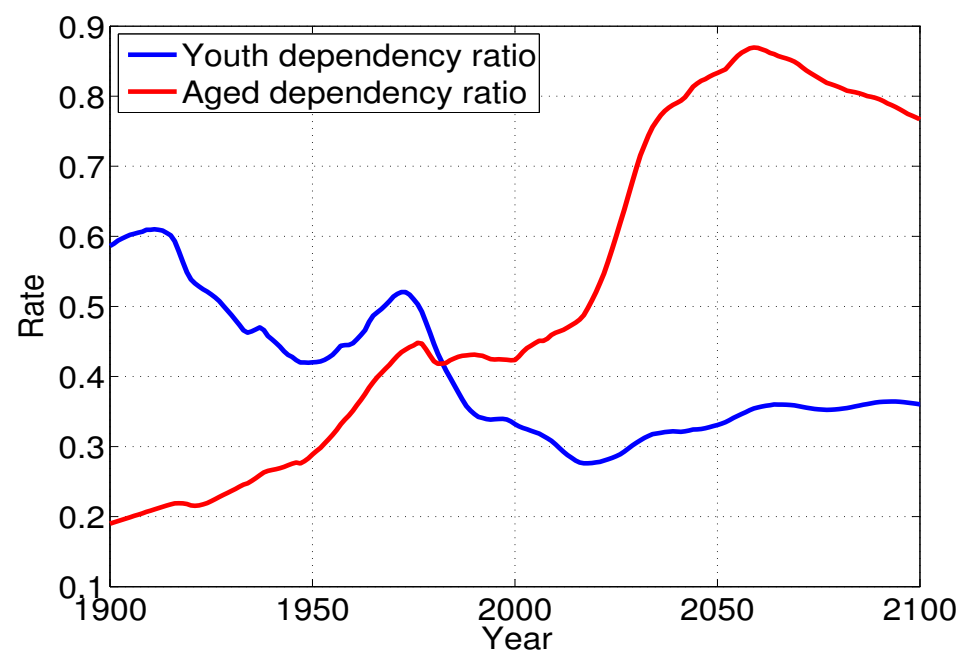

(b) Youth and aged dependency ratios

Figure 7: Demographics from year 1900 to 2100, Austria

Note: Aged dependency ratio is calculated using age groups 18-61 and 62+. 